\title{
S-Adenosylmethionine for osteoarthritis of the knee or hip (Review)
}

Rutjes AWS, Nüesch E, Reichenbach S, Jüni P

Rutjes AWS, Nüesch E, Reichenbach S, Jüni P.

S-Adenosylmethionine for osteoarthritis of the knee or hip.

Cochrane Database of Systematic Reviews 2009, Issue 4. Art. No.: CD007321.

DOI: 10.1002/14651858.CD007321.pub2. 
TABLE OF CONTENTS

HEADER 1

ABSTRACT

PLAIN LANGUAGE SUMMARY

SUMMARY OF FINDINGS

BACKGROUND

OBJECTIVES

METHODS

Figure 1.

RESULTS

Figure 2.

Figure 3.

Figure 4.

Figure 5.

Figure 6.

DISCUSSION

AUTHORS' CONCLUSIONS

ACKNOWLEDGEMENTS

REFERENCES

CHARACTERISTICS OF STUDIES

DATA AND ANALYSES

Analysis 1.1. Comparison $1 \mathrm{~S}$-Adenosylmethionine versus placebo, Outcome 1 Pain.

Analysis 1.2. Comparison $1 \mathrm{~S}$-Adenosylmethionine versus placebo, Outcome 2 Function.

Analysis 1.3. Comparison $1 \mathrm{~S}$-Adenosylmethionine versus placebo, Outcome 3 Number of patients experiencing any adverse event.

Analysis 1.4. Comparison $1 \mathrm{~S}$-Adenosylmethionine versus placebo, Outcome 4 Number of patients who withdrew because of adverse events.

APPENDICES

WHAT'S NEW

CONTRIBUTIONS OF AUTHORS

DECLARATIONS OF INTEREST

SOURCES OF SUPPORT

DIFFERENCES BETWEEN PROTOCOL AND REVIEW

INDEX TERMS 
[Intervention Review]

\section{S-Adenosylmethionine for osteoarthritis of the knee or hip}

Anne WS Rutjes ${ }^{1}$, Eveline Nüesch ${ }^{1}$, Stephan Reichenbach ${ }^{2}$, Peter Jüni ${ }^{1}$

1Division of Clinical Epidemiology and Biostatistics, Institute of Social and Preventive Medicine, University of Bern, Bern, Switzerland.

2Department for Rheumatology, Clinical Immunology, and Allergology, University Hospital, Bern, Switzerland

Contact address: Anne WS Rutjes, Division of Clinical Epidemiology and Biostatistics, Institute of Social and Preventive Medicine, University of Bern, Finkenhubelweg 11, Bern, 3012, Switzerland. arutjes@ispm.unibe.ch, rutjes@negrisud.it.

Editorial group: Cochrane Musculoskeletal Group.

Publication status and date: New, published in Issue 1, 2010.

Citation: Rutjes AWS, Nüesch E, Reichenbach S, Jüni P. S-Adenosylmethionine for osteoarthritis of the knee or hip. Cochrane Database of Systematic Reviews 2009, Issue 4. Art. No.: CD007321. DOI: 10.1002/14651858.CD007321.pub2.

Copyright @ 2010 The Cochrane Collaboration. Published by John Wiley \& Sons, Ltd.

\section{A B S T R A C T}

\section{Background}

Osteoarthritis is the most common form of joint disease and the leading cause of pain and disability in the elderly. S-Adenosylmethionine may be a viable treatment option but the evidence about its effectiveness and safety is equivocal.

\section{Objectives}

We set out to compare S-Adenosylmethionine (SAMe) with placebo or no specific intervention in terms of effects on pain and function and safety outcomes in patients with knee or hip osteoarthritis.

\section{Search methods}

We searched CENTRAL, MEDLINE, EMBASE, CINAHL and PEDro up to 5 August 2008, checked conference proceedings and reference lists, and contacted authors.

\section{Selection criteria}

Randomised or quasi-randomised controlled trials that compared SAMe at any dosage and in any formulation with placebo or no intervention in patients with osteoarthritis of the knee or hip.

\section{Data collection and analysis}

Two independent authors extracted data using standardised forms. We contacted investigators to obtain missing outcome information. We calculated standardised mean differences (SMDs) for pain and function, and relative risks for safety outcomes. We combined trials using inverse-variance random-effects meta-analysis.

\section{Main results}

Four trials including 656 patients were included in the systematic review, all compared SAMe with placebo. The methodological quality and the quality of reporting were poor. For pain, the analysis indicated a small SMD of $-0.17(95 \% \mathrm{Cl}-0.34$ to 0.01$)$, corresponding to a difference in pain scores between SAMe and placebo of $0.4 \mathrm{~cm}$ on a $10 \mathrm{~cm}$ VAS, with no between trial heterogeneity $(12=0)$. For function, the analysis suggested a SMD of $0.02(95 \% \mathrm{Cl}-0.68$ to 0.71$)$ with a moderate degree of between-trial heterogeneity $(12=54 \%)$. The meta-analyses of the number of patients experiencing any adverse event, and withdrawals or drop-outs due to adverse events, resulted in relative risks of 1.27 $(95 \% \mathrm{Cl} 0.94$ to 1.71$)$ and $0.94(95 \% \mathrm{Cl} 0.48$ to 1.86$)$, respectively, but confidence intervals were wide and tests for overall effect were not significant. No trial provided information concerning the occurrence of serious adverse events. 


\section{Authors' conclusions}

The current systematic review is inconclusive, hampered by the inclusion of mainly small trials of questionable quality. The effects of SAMe on both pain and function may be potentially clinically relevant and, although effects are expected to be small, deserve further clinical evaluation in adequately sized randomised, parallel-group trials in patients with knee or hip osteoarthritis. Meanwhile, routine use of SAMe should not be advised.

\section{PLAIN LANGUAGE SUMMARY}

\section{S-Adenosylmethionine (SAMe) for osteoarthritis}

This summary of a Cochrane review presents what we know from research about the effect of S-Adenosylmethionine on osteoarthritis.

\section{The review shows that in people with osteoarthritis:}

- We are uncertain whether S-Adenosylmethionine affects pain or your ability to use your knee because of the low to moderate quality of the evidence.

- S-Adenosylmethionine may not have any side effects. We often do not have precise information about side effects and complications. This is particularly true for rare but serious side effects.

\section{What is osteoarthritis and what is S-Adenosylmethionine (SAMe)?}

Osteoarthritis $(O A)$ is a disease of the joints, such as your knee or hip. When the joint loses cartilage, the bone grows to try to repair the damage. Instead of making things better, however, the bone grows abnormally and makes things worse. For example, the bone can become misshapen and make the joint painful and unstable. This can affect your physical function or ability to use your knee.

S-Adenosylmethionine is popular dietary supplement available over the counter in drug stores or health food stores. It is also a naturally occurring chemical that is produced in the body. SAMe is not found in foods, so it must be taken as a supplement.

\section{Best estimate of what happens to people with osteoarthritis who take S-Adenosylmethionine (SAMe)}

\section{Pain}

- People with S-Adenosylmethionine and people with placebo are equally likely to respond to treatment (difference of $0 \%$ ). This could be the result of chance.

- People who took S-Adenosylmethionine had an improvement in their pain of about 2 on a scale from 0 (no pain) to 10 (extreme pain) after using it up to 3 months.

- People who took a placebo had an improvement in their pain of also about 2 on a scale from 0 (no pain) to 10 (extreme pain) after using it up to 3 months.

\section{Physical Function}

- People with S-Adenosylmethionine and people with placebo are equally likely to respond to treatment (difference of $0 \%$ ). This could be the result of chance.

- People who took S-Adenosylmethionine had an improvement in their physical function of about 1 on a scale of 0 (no disability) to 10 (extreme disability) after using it up to 3 months.

- People who took a placebo had an improvement in their physical function of also about 1 on a scale of 0 (no disability) to 10 (extreme disability) after using it up to 3 months.

\section{Side effects}

- 4 more people experienced side effects with S-Adenosylmethionine than with placebo (difference of $4 \%$ ). This could be the result of chance.

- 19 people out of 100 who used S-Adenosylmethionine experienced side effects (19\%). 
- 15 people out of 100 who used a placebo experienced side effects (15\%). 


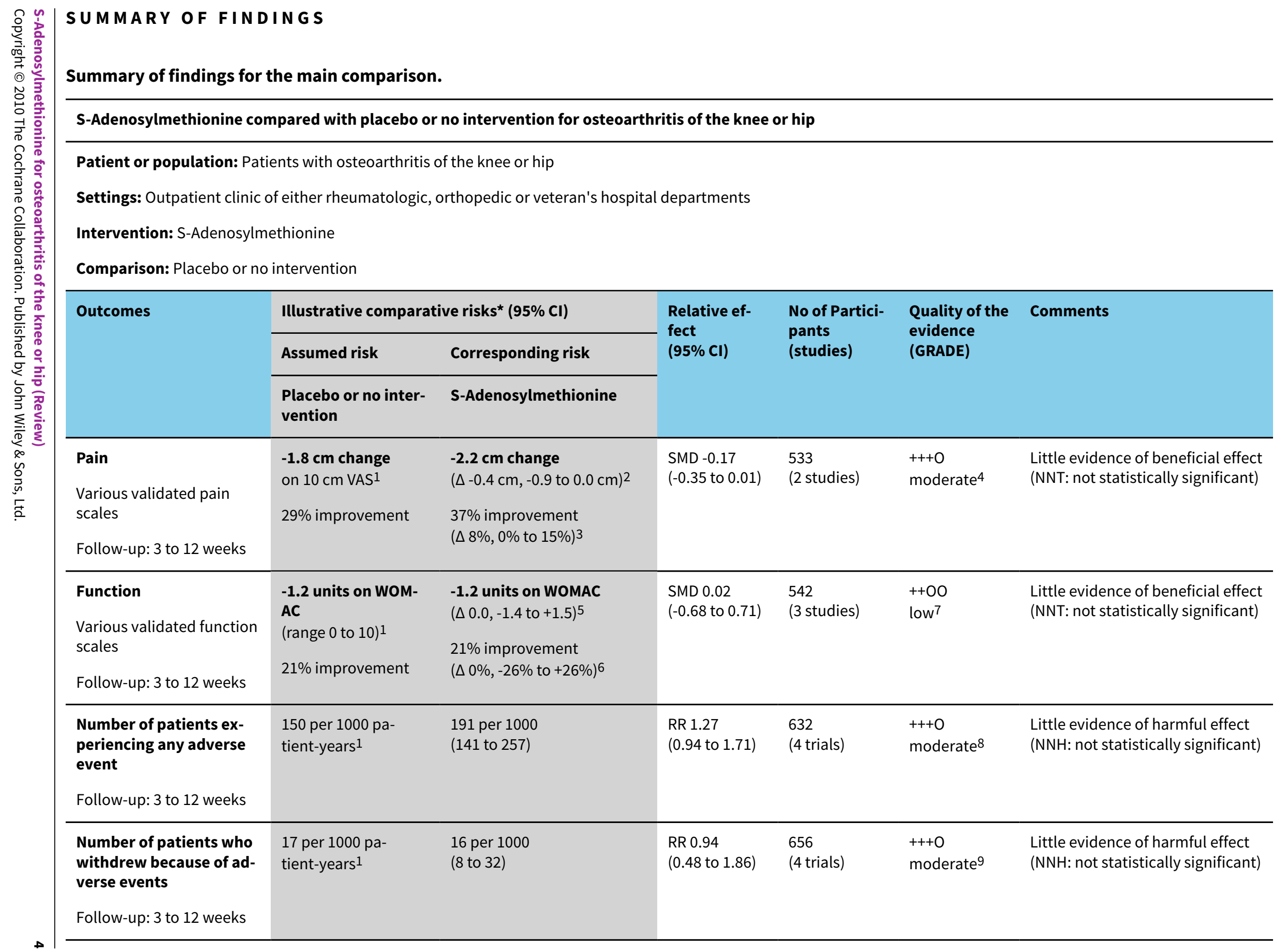


${ }^{*}$ The basis for the assumed risk (e.g. the median control group risk across studies) is provided in footnotes. The corresponding risk (and its $95 \%$ confidence interval) is based on the assumed risk in the comparison group and the relative effect of the intervention (and its $95 \% \mathrm{Cl}$ ).

CI: Confidence interval; GRADE: GRADE Working Group grades of evidence (see explanations); SMD: standardised mean difference; NNT: number needed to treat; NNH: number needed to harm

\section{GRADE Working Group grades of evidence}

High quality (++++): Further research is very unlikely to change our confidence in the estimate of effect.

Moderate quality (+++O): Further research is likely to have an important impact on our confidence in the estimate of effect and may change the estimate.

Low quality (++00): Further research is very likely to have an important impact on our confidence in the estimate of effect and is likely to change the estimate.

Very low quality (+000): We are very uncertain about the estimate.

1 Median reduction as observed across control groups in large osteoarthritis trials (Nüesch 2009).

2 Standardised mean differences (SMDs) were back-transformed onto a $10 \mathrm{~cm}$ visual analogue scale (VAS) on the basis of a typical pooled SD of $2.5 \mathrm{~cm}$ in trials that assessed pain using a VAS, and expressed as change based on an assumed standardised reduction of 0.72 standard deviation units in the control group.

3 The median observed pain score at baseline across control groups in large osteoarthritis trials was $6.1 \mathrm{~cm}$ on a $10 \mathrm{~cm}$ VAS (Nüesch 2009).

4 Downgraded ( 1 level) because analyses was not according to intention-to-treat principle, 2 out of 4 trials reported this outcome, potentially leading to selective outcome reporting bias, 1 out of 2 trials used adequate, 1 used unclear concealment of allocation methods, possible indirectness of evidence (indirect population) in 1 out of 2 studies.

5 Standardised mean differences (SMDs) were back-transformed onto a 0 to 10 standardised WOMAC function score on the basis of a typical pooled SD of 2.1 in trials that assessed function on WOMAC function scale and expressed as change based on an assumed standardised reduction of 0.58 standard deviation units in the control group.

6 The median observed standardised WOMAC function score at baseline across control groups in large osteoarthritis trials was 5.6 units (Nüesch 2009 ).

7 Downgraded (2 levels) because: analyses was not according to intention-to-treat principle, presence of moderate between-trial heterogeneity, possible indirectness of evidence (indirect population) in 2 out of 3 studies, the confidence interval is wide and crossed no difference, 1 out of 3 trials used adequate, 2 used unclear concealment of allocation methods.

8 Downgraded (1 level) because the confidence interval crosses no difference, in 1 out of 4 trials analyses was not according to intention-to-treat principle. 9 Downgraded ( 1 level) because the confidence interval is wide and crossed no difference. 


\section{B A C K G R O U N D}

Osteoarthritis is a degenerative disease characterised by focal areas of loss of articular cartilage in synovial joints, subchondral bone changes, osteophyte formation at the joint margins, thickening of the joint capsule and mild synovitis (Altman 1996). Symptoms include pain, stiffness and decreased range of motion, limiting daily activities and reducing quality of life. To manage the symptoms of osteoarthritis, patients and healthcare providers often resort to multiple approaches, including lifestyle modifications, medications, exercise or surgery. Non-steroidal antiinflammatory drugs (NSAIDs) are the mainstay of management for osteoarthritic pain, but may cause serious gastrointestinal and cardiovascular adverse events.

Beneficial effects of the dietary supplement S-Adenosylmethionine (SAMe) have been intensively advertised. Within a few years the supplement has become popular, surrounded by countless claims concerning its effectiveness with fewer side effects. SAMe is proposed for use as an antidepressant, a medication for cholestasis and liver disorders, a treatment for migraines, and therapy for fibromyalgia and osteoarthritis. The rationale for a general therapeutic application of SAMe stems from the hypothesis that subnormal biologically active levels of this substance will be normalised by a parenteral or peroral administration in a variety of organ systems. SAMe is deemed to induce beneficial changes in the individual, whose problems - at least in part - are related to a relative deficiency of the compound (Fetrow 2001). In osteoarthritis, the exact mechanism remains controversial. It is suggested that there is a mismatch between generative and degenerative forces that govern cartilage formation, partly because of a malfunction in proteoglycan synthesis. One in vitro study of SAMe (Harmand 1987) suggested that it may favourably affect the synthesis of proteoglycans. Additional mechanisms of SAMe in reducing pain in osteoarthritis include a reduction of inflammation and direct analgesic effects at central or peripheral levels, potentially mediated through a cyclo-oxygenase inhibition.

Initial studies with SAMe used the parenteral route exclusively due to the instability of the oral form. As additional work allowed the development of a stable oral form of SAMe, further studies tested the effectiveness of the oral form in the management of several medical conditions including osteoarthritis. Four reviews on SAMe for osteoarthritis have been published (di Padova 1987; Hardy 2002; Soeken 2002; Witte 2002). Three are systematic reviews including a meta-analysis (Hardy 2002; Soeken 2002; Witte 2002) and the fourth is a narrative, general overview of articles (di Padova 1987). Similar conclusions were drawn in these reviews: that the results of the available studies were heterogeneous and did not allow firm claims to be made about the effectiveness of SAMe in the management of osteoarthritis.

\section{OB JECTIVES}

We set out to compare S-Adenosylmethionine (SAMe) with placebo or no specific intervention in terms of effects on pain and function and safety outcomes in patients with knee or hip osteoarthritis and to explore whether potential variation between trials could be explained by biases affecting individual trials or by publication bias.

\section{METHODS}

\section{Criteria for considering studies for this review \\ Types of studies}

Randomised or quasi-randomised controlled trials were eligible. Trials using an unpredictable allocation sequence were considered as randomised.

\section{Types of participants}

Trials including at least $75 \%$ of patients with clinically and/or radiologically confirmed osteoarthritis of the knee or hip. We excluded trials which evaluated SAMe after knee or hip surgery.

\section{Types of interventions}

We considered trials involving administration of SAdenosylmethionine at any dosage and in any formulation. Eligible control interventions were placebo or a non-intervention control (usual care).

\section{Types of outcome measures}

\section{Main outcomes}

Main outcomes were pain and function, as currently recommended for osteoarthritis trials (Altman 1996; Pham 2004). If data on more than one pain scale were provided for a trial, we referred to a previously described hierarchy of pain-related outcomes (Jüni 2006; Reichenbach 2007) and extracted data on the pain scale that is highest on this list:
1. Global pain
2. Pain on walking
3. WOMAC osteoarthritis index pain subscore
4. Composite pain scores other than WOMAC
5. Pain on activities other than walking
6. Rest pain or pain during the night
7. WOMAC global algofunctional score
8. Lequesne osteoarthritis index global score
9. Other algofunctional scale
10.Patient's global assessment
11.Physician's global assessment

If data on more than one function scale were provided for a trial, we extracted data according to the hierarchy presented below.
1. Global disability score
2. Walking disability
3. WOMAC disability subscore
4. Composite disability scores other than WOMAC
5. Disability other than walking
6. WOMAC global scale
7. Lequesne osteoarthritis index global score
8. Other algofunctional scale
9. Patient's global assessment
10.Physician's global assessment

If pain or function outcomes were reported at several time points, we extracted the measure at the end of the treatment period. 


\section{Secondary outcomes}

Secondary outcomes included the number of patients experiencing any adverse event, patients who were withdrawn or dropped out because of adverse events, and patients experiencing any serious adverse events. We extracted end of trial data for these outcomes. We defined serious adverse events as events resulting in inpatient hospitalisation, prolongation of hospitalisation, persistent or significant disability, congenital abnormality/birth defect of offspring, life-threatening events or death.

\section{Search methods for identification of studies}

\section{Electronic searches}

We searched the Cochrane Central Register of Controlled Trials (CENTRAL) (The Cochrane Library 2008, issue 3), MEDLINE (1966 to 5 August 2008) and EMBASE (1975 to 5 August 2008) through the Ovid platform (www.ovid.com), and CINAHL (1937 to 5 August 2008) through EBSCOhost, using truncated variations of preparation names, including brand names, combined with truncated variations of terms related to osteoarthritis, as well as MESH headings. We applied a validated methodological filter for controlled clinical trials (Dickersin 1994). The specific search algorithms are displayed in Appendix 1 for MEDLINE, EMBASE and CINAHL, and in Appendix 2 for CENTRAL.

\section{Searching other resources}

We manually searched conference proceedings. We used Science Citation Index to retrieve reports citing the relevant articles. We screened reference lists of all obtained articles, including related reviews. We contacted content experts and trialists and asked them for relevant references. Finally, we searched several clinical trial registries (www.clinicaltrials.gov, www.controlled-trials.com, www.actr.org.au, www.umin.ac.jp/ctr) to identify ongoing trials.

The last update of the manual search was on 28 July 2008.

\section{Data collection and analysis}

\section{Selection of studies}

Two review authors (AR and EN) independently evaluated all yielded titles and abstracts for eligibility (see Figure 1). We resolved disagreements by discussion. We applied no language restrictions. In case of multiple reports relating to the same trial, we considered all reports.

\section{Figure 1. Study flow chart}

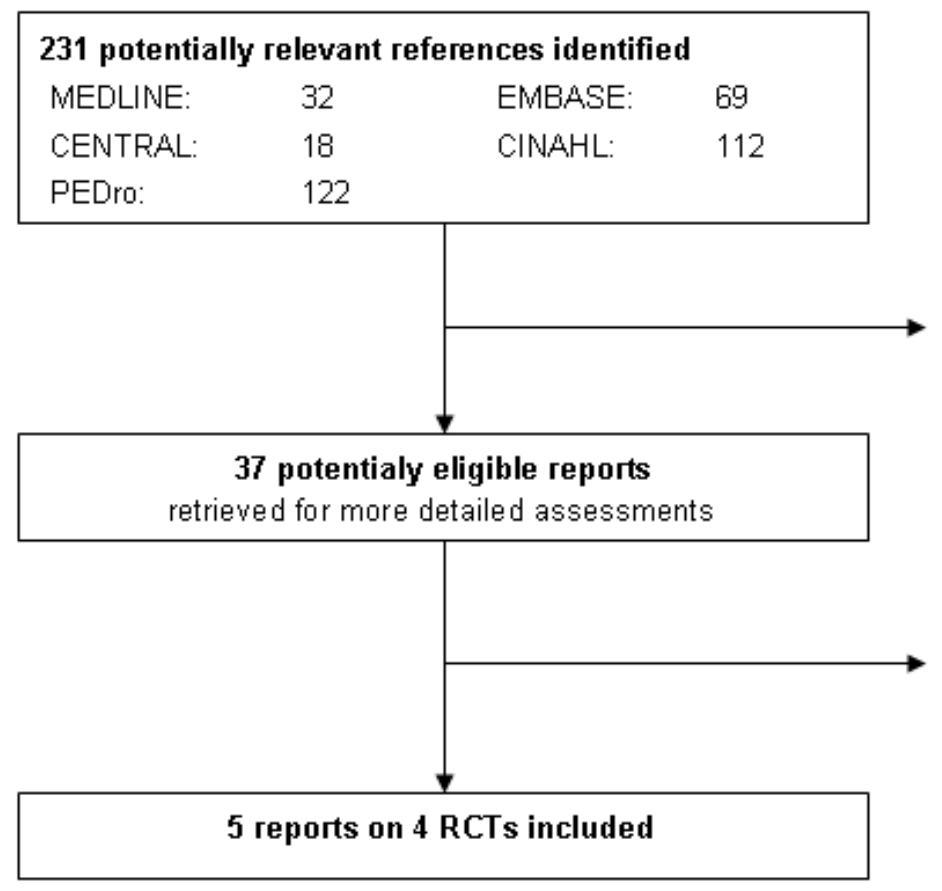

\section{4 reports excluded for further review}

- Duplicate reference $n=43$

- Not relevant to knee or hip osteoarthritis $n=50$

- Not relevant to S-adenosylmethionine $n=19$

- Review, editorial or guideline $n=78$

- Animal study or absence of randomisation $n=4$

\section{2 reports excluded based on full text screening}

- Not relevant to knee or hip osteoarthritiss $n=3$

- Not relevant to S-adenosylmethionine $n=5$

- Use of active control $n=12$

- Review, editorial or guideline $n=11$

- Animal study or absence of randomisation $n=1$

\section{Data extraction and management}

Two review authors (AR and SR or EN) independently extracted trial information using a standardised, piloted extraction form accompanied by a codebook. We resolved disagreements by discussion. We extracted the generic and the trade name of SAMe, the type of control used, dosage, frequency and duration of treatment, patient characteristics (average age, gender, mean duration of symptoms, type of joints affected), type of pain- and function-related outcome extracted, trial design, trial size, duration of follow up, type and source of financial support and publication status from trial reports. When necessary, we approximated means and measures of dispersion from figures in the reports. For crossover trials, we extracted data from the first period only because of possible carry-over effects. Whenever possible, we used results from an intention-to-treat analysis. If effect sizes could not be calculated, we contacted the authors for additional data. 


\section{Assessment of risk of bias in included studies}

Two review authors (AR and SR or EN) independently assessed randomisation, blinding and adequacy of analyses (Jüni 2001). We resolved disagreements by consensus. We assessed two components of randomisation: generation of allocation sequences and concealment of allocation. The generation was considered adequate if it resulted in unpredictable allocation sequences; mechanisms considered adequate include random-number tables, computer-generated random numbers, minimisation, coin tossing, shuffling of cards and drawing of lots. Trials using an unpredictable allocation sequence were considered randomised; trials using potentially predictable allocation mechanisms, such as alternation or the allocation of patients according to date of birth, were considered quasi-randomised. We considered allocation concealment adequate if the investigators responsible for patient selection were unable to suspect before allocation which treatment was next; methods considered adequate include central randomisation, pharmacy controlled randomisation using identical pre-numbered containers, and sequentially numbered, sealed, opaque envelopes. We considered blinding of patients adequate if the preparations were explicitly described as indistinguishable or if a double-dummy technique was used. We considered analyses adequate if all randomised patients were included in the analysis according to the intention-to-treat principle. Finally, we used GRADE to describe the quality of the overall body of evidence (Guyatt 2008; Higgins 2008), defined as the extent of confidence in the estimated treatment benefits and harms.

\section{Data synthesis}

We summarised continuous outcomes using standardised mean differences (SMD), with the differences in mean values at the end of follow up across treatment groups divided by the pooled standard deviation. If differences in mean values at the end of the follow up were unavailable, we used differences in mean changes. If some of the required data were unavailable, we used approximations as previously described (Reichenbach 2007). A SMD of -0.20 standard deviation units can be considered a small difference between experimental and control group, a SMD of -0.50 a moderate difference, and -0.80 a large difference (Cohen 1988; Jüni 2006). SMDs can also be interpreted in terms of the percent of overlap of the experimental group's scores with scores of the control group. A SMD of -0.20 indicates an overlap in the distributions of pain or function scores in about $85 \%$ of cases, a SMD of -0.50 in approximately $67 \%$, and a SMD of -0.80 in about $53 \%$ of cases (Cohen 1988; Jüni 2006). On the basis of a median pooled SD of $2.5 \mathrm{~cm}$ found in large-scale osteoarthritis trials that assessed pain using a $10 \mathrm{~cm}$ visual analogue scale (VAS) (Nüesch 2009), SMDs of $-0.20,-0.50$ and -0.80 correspond to approximate differences in pain scores between experimental and control groups of $0.5,1.25$ and $2.0 \mathrm{~cm}$ on a $10 \mathrm{~cm}$ VAS. SMDs for function were back transformed to a standardised WOMAC disability score (Bellamy 1995) ranging from 0 to 10 , on the basis of a median pooled SD of 2.1 units observed in large-scale osteoarthritis trials (Nüesch 2009). We expressed binary outcomes as risk ratios (RR).

We used standard inverse-variance random-effects meta-analysis to combine the trials (DerSimonian 1986). We quantified heterogeneity between trials using the 12 statistic (Higgins 2003), which describes the percentage of variation across trials that is attributable to heterogeneity rather than to chance and the corresponding $x^{2}$ test. $\left.\right|^{2}$ values of $25 \%, 50 \%$ and $75 \%$ may be interpreted as low, moderate and high between-trial heterogeneity, although the interpretation of $\mathrm{I}^{2}$ depends on the size and number of trials included (Rucker 2008). Then, we converted SMDs of pain intensity and function to odds ratios (Chinn 2000) to derive numbers needed to treat (NNT) to cause one additional treatment response on pain or function as compared with control, and numbers needed to harm (NNH) to cause one additional adverse outcome. We defined treatment response as a 50\% improvement in scores (Clegg 2006), which corresponds to an average decrease of 1.2 standard deviation units (Nüesch 2009). With a median standardised pain intensity at baseline of 2.4 standard deviation units and a median standardised decrease in pain scores of 0.72 standard deviation units observed in large osteoarthritis trials (Nüesch 2009), we calculated that a median of $31 \%$ of patients in the control group would achieve an improvement of pain scores of $50 \%$ or more. This percentage was used as the control group response rate to calculate NNTs for treatment response on pain. Based on the median standardised WOMAC function score at baseline of 2.7 standard deviation units and the median standardised decrease in function scores of 0.58 standard deviation units (Nüesch 2009), $26 \%$ of patients in the control group would achieve a reduction in function of $50 \%$ or more. Again, this percentage was used as the control group response rate to calculate NNTs for treatment response on function. We used median risks of 150 patients with adverse events per 1000 patient-years, four patients with serious adverse events per 1000 patient-years and 17 drop-outs due to adverse events per 1000 patient-years, observed in placebo groups in large osteoarthritis trials (Nüesch 2009), to calculate NNHs for safety outcomes.

All $P$ values are two-sided. We performed the data analysis in RevMan version 5 (RevMan 2008) and STATA version 10.1 (StataCorp, College Station, Texas).

\section{RE S U L T S}

\section{Description of studies}

We identified 231 references to articles and considered 37 to be potentially eligible (Figure 1). Five reports describing four completed trials in 656 patients met our inclusion criteria. Contacting experts and checking conference readings and trial registers did not result in the identification of additional RCTs.

Three small sized trials used a two-arm parallel-group design to compare SAMe with placebo (Bradley 1994; König 1990; Montrone 1985). A large sized multicentre study by Caruso and Pietrogrande used a three-arm parallel-group design to compare SAMe with naproxen and placebo (Caruso 1987). The trial arm involving naproxen was excluded from this review. Duration of the studies ranged from three (Montrone 1985) to 12 weeks (König 1990); follow up was at the end of trial in all studies.

In all studies patients had a clinical severity requiring simple non-surgical treatments (Jüni 2006), three trials included patient with functional classes II and III and definite radiological signs of osteoarthritis, but one trial included patients without typical radiographic signs (König 1990). In two trials, only patients with osteoarthritis of the knee were included (Bradley 1994; König 1990), while the trial by Montrone 1985 included both: 51 patients (67\%) with knee osteoarthritis and $25(33 \%)$ patients with hip osteoarthritis. Caruso 1987 included knee (55\%), hip (24\%), hand 
(7\%) and spine osteoarthritis (14\%). Despite the description of an adequately concealed randomisation with stratification for study centre, the patient population in the two centres in Bradley 1994 differed. At one site, the majority of the patients were female (85\%) with an average age of 58 years and an average disease duration of 10.9 years. At the other site, only $21 \%$ of the patients were female with a average age of 63 years and an average disease duration of 12.4 years.

SAMe and placebo were applied orally in all studies. However, one study started with intravenous SAMe for the first five days before switching to an oral formulation of the interventions (Bradley 1994). Oral doses of SAMe used were $200 \mathrm{mg}$ three times per day (Bradley 1994), 400 mg three times per day (König 1990; Montrone 1985) or $400 \mathrm{mg}$ six times per day (Caruso 1987). One trial allowed the use of analgesics (Bradley 1994), another explicitly did not (Caruso 1987), and two trials did not report on analgesic co-interventions (König 1990; Montrone 1985).
We excluded 12 studies because SAMe was compared to active control interventions: ibuprofen was used in six studies (Capretto1985; Ceccato 1980; Cucinotta 1980; Glorioso 1985; Marcolongo 1985; Muller-Fassbender 1987), and naproxen, aspirin, indomethacin, piroxicam, celecoxib, sulindac and indomethacin were used in one study each as comparators (Caroli 1980; Domljan 1989; Maccagno 1987; Najm 2004; Pellegrini 1980; Vetter 1987). The 'Characteristics of excluded studies' table presents the main reasons for exclusion of other studies.

\section{Risk of bias in included studies}

One study reported adequate generation of the randomisation sequence and adequate allocation concealment using coded pharmacy (Bradley 1994, Figure 2). The study of Caruso 1987 reported the use of block randomisation but did not report how blocks were generated, nor the method used for concealment of allocation. The other two studies were unclear about the methods used to randomise patients (König 1990; Montrone 1985).

Figure 2. Methodological quality summary: review authors' judgements about each methodological quality item for each included study.

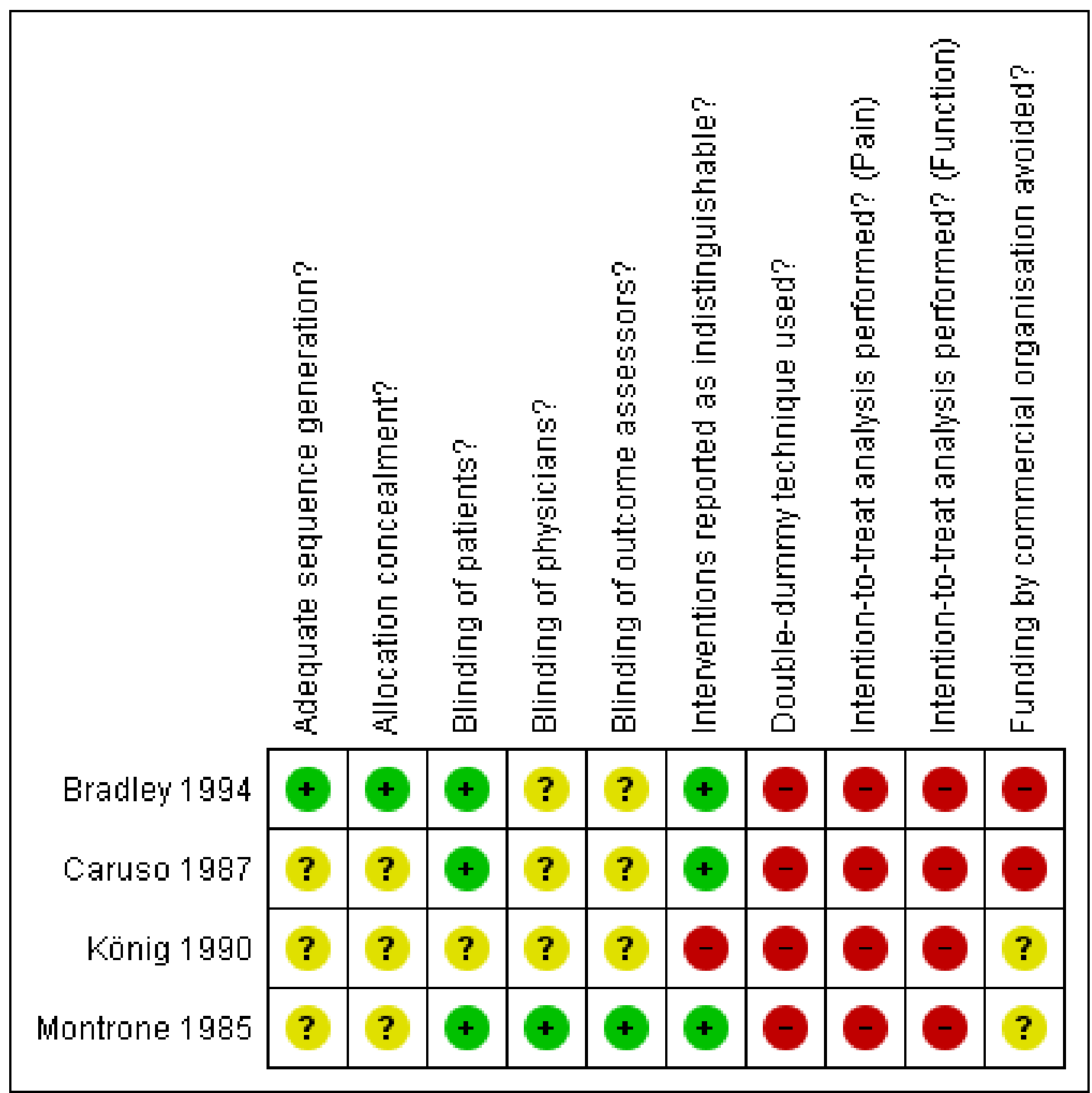


All trials were described as double-blind. Three trials reported the use of indistinguishable interventions to blind patients (Bradley 1994; Caruso 1987; Montrone 1985), but only Montrone 1985 explicitly described that patients, physicians and assessors were blinded. In Bradley 1994 and Caruso 1987 only adequate blinding of patients could be assumed. The remaining study did not describe blinding of patients or physicians, nor did it describe the use of an indistinguishable placebo control (König 1990).

None of the trials was considered to have performed an intentionto-treat analysis for any of the primary outcomes. All trials explicitly reported exclusion of randomised patients. Percentages of exclusions ranged from $5.2 \%$ to $18 \%$ in experimental groups and from $0 \%$ to $8 \%$ in control groups. One trial did not report the overall number of patients randomly allocated and the percentage of exclusions could not be determined (Bradley 1994).

Three trials failed to report the specification of a primary outcome and failed to present power calculations. The fourth trial by Bradley 1994 reported three separate pain scales as primary outcomes. Although this trial also reported a protocol based sample size calculation, it was unclear on which of the three pain outcomes the difference used in the calculation was based (Bradley 1994).

Two trials were funded by a manufacturer of SAMe (Bradley 1994; Caruso 1987), whereas the source of funding was unclear in the the other two trials.

\section{Effects of interventions}

See: Summary of findings for the main comparison

\section{Pain intensity}

Two trials with two comparisons (533 patients) contributed to the meta-analysis of pain outcomes (Figure 3). The analysis suggested a small SMD of $-0.17(95 \% \mathrm{Cl}-0.35$ to 0.01$)$ for pain which corresponds to a difference in pain scores of $0.4 \mathrm{~cm}$ on a $10 \mathrm{~cm}$ VAS, a difference in improvement from baseline of $8 \%(95 \% \mathrm{Cl} 0 \%$ to $+15 \%)$ between SAMe and control (see 'Summary of findings for the main comparison'). An 12 of $0 \%$ indicated the absence of between-trial heterogeneity ( $P$ for heterogeneity $=0.92$ ), which was confirmed by visual inspection.

Figure 3. Forest plot of 2 trials comparing the effects of S-Adenosylmethionine and control (placebo or no intervention) on knee or hip pain. Values on $\mathrm{x}$-axis denote standardised mean differences.

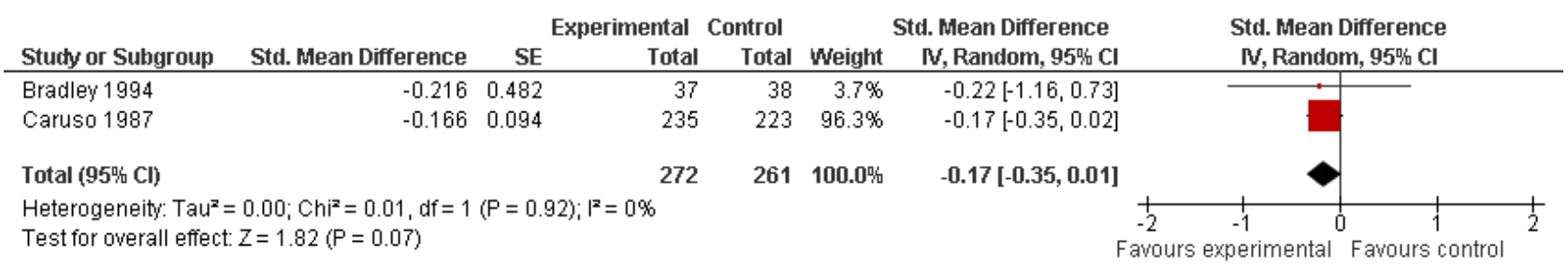

\section{Function}

Three trials (542 patients) contributed to the meta-analyses of function (Figure 4). The analysis suggested a negligible SMD of $0.02(95 \% \mathrm{Cl}-0.68$ to 0.71 , see 'Summary of findings for the main comparison'). An $1^{2}$ of $54 \%$ indicated a moderate degree of between-trial heterogeneity ( $\mathrm{P}$ for heterogeneity $=0.11$ ). On visual inspection, the variation could be explained by the trial by König
1990 that estimated an effect size favouring control. Excluding König 1990 in a sensitivity analysis, we found a SMD of $-0.15(95 \% \mathrm{Cl}$ -0.33 to 0.03 ), which corresponds to a difference in function scores of 0.3 units on a standardised WOMAC disability scale ranging from 0 to 10 and a difference in improvement of $6 \%(95 \% \mathrm{Cl} 0 \%$ to $+13 \%$ ) between SAMe and control, and a reduction of between-trial heterogeneity to $0 \%$ ( $P$ for heterogeneity $=0.11$ ).

\section{Figure 4. Forest plot of 3 trials comparing the effects of S-Adenosylmethionine and control (placebo or no intervention) on function. Values on $\mathrm{x}$-axis denote standardised mean differences.}

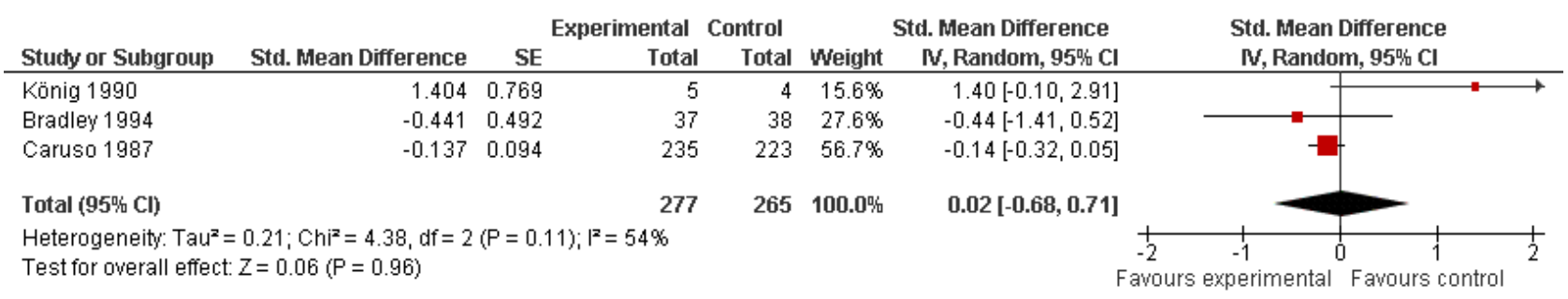

\section{Safety}

All trials (623 patients) contributed to the meta-analysis of patients experiencing any adverse event (Figure 5). The analysis suggested a RR of $1.27(95 \% \mathrm{Cl} 0.94$ to 1.71$)$. An $\mathrm{I}^{2}$ of $0 \%$ suggested an absence of between-trial heterogeneity ( $P$ for heterogeneity $=0.39$ ). All trials (656 patients) contributed to the meta-analysis of patients withdrawn or dropped out because of adverse events (Figure 6). The analysis yielded a RR of 0.94 but confidence intervals were wide (95\% $\mathrm{Cl} 0.48$ to 1.86 ). An $\mathrm{I}^{2}$ of $0 \%$ again suggested an absence of between-trial heterogeneity ( $P$ for heterogeneity $=0.76$ ). None of the trials contributed to the meta-analysis of patients experiencing any serious adverse event. 
Figure 5. Forest plot of 4 trials comparing patients experiencing any adverse event between $\mathrm{S}$-adenosylmethionine and control (placebo or no intervention). Values on $\mathrm{x}$-axis denote risks ratios.

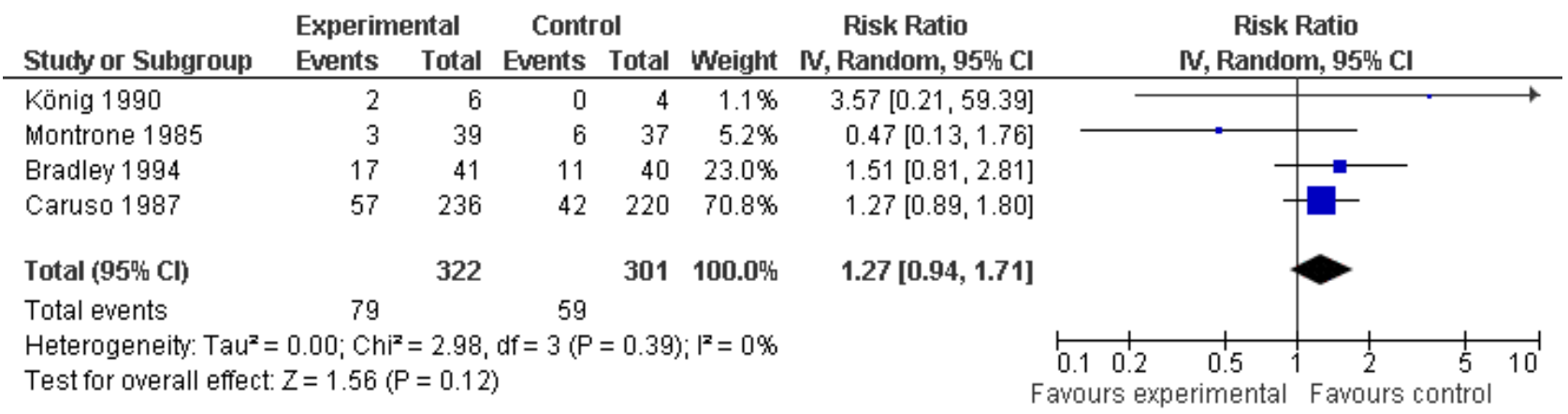

Figure 6. Forest plot of 4 trials comparing patients who withdrew because of adverse events between $\mathbf{S -}$ adenosylmethionine and control (placebo or no intervention). Values on $\mathrm{x}$-axis denote risks ratios.

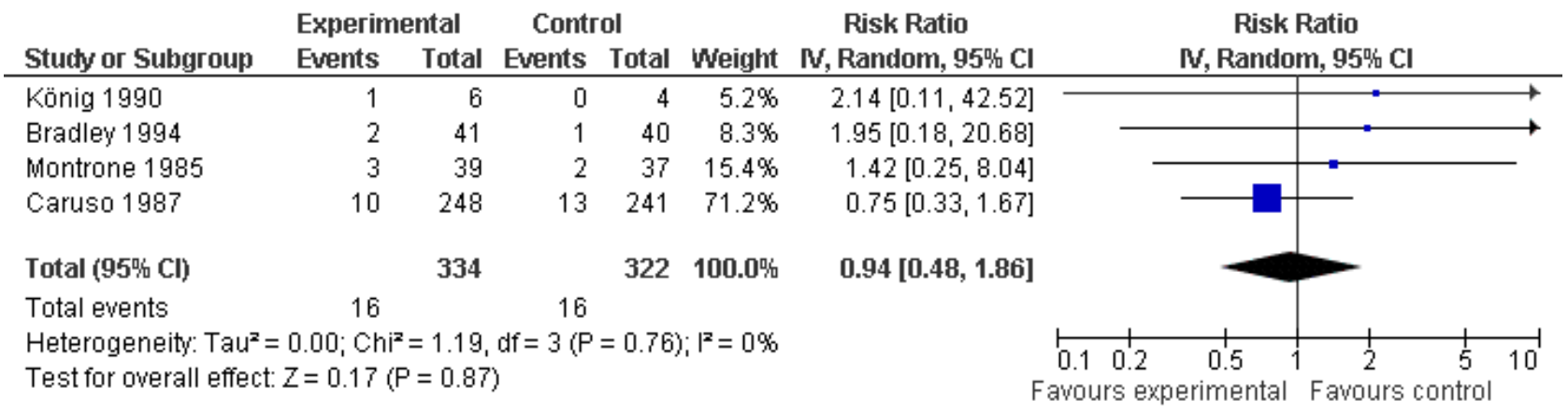

\section{DISCUSSION}

\section{Summary of main results}

Our systematic review of trials comparing S-Adenosylmethionine (SAMe) with a placebo control revealed a lack of adequately sized, methodologically sound and appropriately reported trials and a moderate degree of heterogeneity between trials reporting function outcomes, which made the interpretation of results difficult. Overall effect sizes for pain and function seemed small. We found little evidence to suggest that SAMe is unsafe, but $95 \%$ confidence intervals $(\mathrm{Cl})$ were wide and therefore inconclusive.

\section{Quality of the evidence}

The methodological quality and the quality of reporting in the trials was poor. All but one had small sample sizes. Insufficient information about the generation of allocation sequences and concealment of allocation was noted in three out of four randomised controlled trials. None of the trials performed analyses according to the intention-to-treat principle. All trials failed to describe serious adverse events, which is concerning. Due to the low number of trials identified, we were unable to explore the effects of dosing, route of administration, methodological quality or type of funding.

\section{Potential biases in the review process}

Our review is based on a broad literature search, and it seems unlikely that we missed relevant trials (Egger 2003). Trial selection and data extraction, including quality assessment, were done independently by two authors to minimise bias and transcription errors (Egger 2001). Components used for quality assessment are validated and reported to be associated with bias (Jüni 2001; Wood 2008). As with any systematic review, our study is limited by the quality of included trials. As indicated above, trials generally suffered from poor methodological quality, inadequate reporting and small sample size. One trial showed an unrealistically large unfavourable standardised mean difference (SMD) for function, which can best be explained by chance, as the study included only nine patients (König 1990). Including this trial in the meta-analysis may result in a slight underestimation of the benefit of SAMe on function. We included a trial described as a double-blind study in a published letter, although the report did not specifically mention the use of randomisation. Exclusion of this study would not have altered any of our conclusions.

\section{Agreements and disagreements with other studies or reviews}

We are aware of two systematic reviews that compared the efficacy of SAMe with placebo on pain and function (Soeken 2002; Witte 2002). In line with our review, the authors did not find a statistical significant improvement in pain (SMD $-0.22,95 \% \mathrm{Cl}-0.69$ to 0.25 in Soeken 2002; $-0.38,95 \% \mathrm{Cl}-0.89$ to 0.12 in Witte 2002). In contrast to our conclusions, Soeken 2002 concluded that SAMe, when compared to placebo, was effective in reducing functional limitations (SMD -0.31, 95\% confidence interval -0.52 to -0.10 ). They further concluded that the tolerability of SAMe was similar to 
that of placebo and greater than that of NSAIDs. The difference in conclusions regarding improvement of function can be explained by differences in outcome definitions and inclusion criteria. Soeken 2002 choose restriction in joint movement as an outcome, whereas we choose a different approach, using a hierarchy developed to minimise the impact of selective reporting of outcomes and to allow for a synthesis of evidence across different studies using divergent definitions of function. In the review of Soeken 2002, only Caruso 1987 contributed to the analysis of function, whereas we could include two additional trials (Bradley 1994 and König 1990). The odds ratio of 1.37 ( $95 \% \mathrm{Cl} 0.81$ to 2.32 ) for patients experiencing adverse events in Soeken 2002 was comparable to our pooled relative ratio of 1.27 ( $95 \% \mathrm{Cl} 0.94$ to 1.71$)$.

\section{AUTHORS' CONCLUSIONS}

\section{Implications for practice}

Routine use of S-Adenosylmethionine (SAMe) should not be recommended until further trials of adequate sample size and methodology suggest a clinically relevant effectiveness.

\section{Implications for research}

To allow unequivocal conclusions to be drawn regarding the effects of SAMe on both pain relief and function, and on safety, additional adequately powered, double-blind, placebo controlled trials should be performed. Special attention needs to be given to the use of adequate randomisation with appropriate concealment of allocation and an analysis according to the intention-to-treat principle. Although a daily intake of $1200 \mathrm{mg}$ (orally) may be a reasonably effective dose with an acceptable safety profile, further clarification of the optimal dose is necessary.

\section{ACKN O WLEDGEMENTS}

We thank the Cochrane Musculoskeletal editorial team for valuable comments and Malcolm Sturdy for database support. We thank Frank Wacker who replied to our queries and attempted to locate files for trials published 18 years ago, but was unable to provide additional outcome data. 


\section{REFERE N CE S}

\section{References to studies included in this review}

Bradley 1994 \{published data only\}

Bradley JD, Flusser D, Katz BP, Schumacher HR Jr, Brandt KD, Chambers MA, et al. A randomized, double blind, placebo controlled trial of intravenous loading with Sadenosylmethionine (SAM) followed by oral SAM therapy in patients with knee osteoarthritis. Journal of Rheumatology 1994;21(5):905-11.

\section{Caruso 1987 \{published data only\}}

Caruso I, Pietrogrande V, Caruso I, Pietrogrande V. Italian double-blind multicenter study comparing Sadenosylmethionine, naproxen, and placebo in the treatment of degenerative joint disease. American Journal of Medicine 1987;83(5A):66-71.

\section{König 1990 \{published data only\}}

König H, Saal J. Quantitatively evaluated magnetic resonance tomography as a therapeutic follow-up of the nonsteroidal antirheumatic ademetionin: a pilot study in patients with gonarthrosis [Quantitativ ausgewertete Kernspintomographie als Therapiekontrolle des nicht-steroidalen Antirheumatikums Ademetionin: Pilotstudie bei Gonarthrose-Patienten]. Rofo: Fortschritte auf dem Gebiet der Röntgenstrahlen und der Nuklearmedizin 1990;152(2):214-9.

Wacker FK, König H. Quantitative evaluation of magnetic resonance imaging in long-term therapy: a pilot study in patients with osteoarthritis of the knee. Acta Pharmaceutica 1993;43:253-60.

\section{Montrone 1985 \{published data only\}}

Montrone F, Fumagalli M, Sarzi Puttini P, Boccassini L, Santandrea S, Volpato R, et al. Double-blind study of Sadenosyl-methionine versus placebo in hip and knee arthrosis. Clinical Rheumatology 1985;4(4):484-5.

\section{References to studies excluded from this review}

Bottiglieri 2002 \{published data only\}

Anonymous. S-adenosyl-L-methionine (SAMe): from the bench to the bedside - molecular basis of a pleiotrophic molecule. SAdenosylmethionine (SAMe): from molecular mechanism to clinical implication: proceedings of a symposium held at the Oxygen Club of California 2001 World Congress, Santa Barbara, CA, March 7-10, 2001. American Journal of Clinical Nutrition 2002;76:1151S-57S.

\section{Caroli 1980 \{published data only\}}

Caroli A, Caroli A. Double-blind study of SAMe (capsules) and aspirin in osteoarthrosis [Studio in doppio cieco SAMe (capsule) - Aspirina nell'osteoartrosi.]. Giornale di Clinica Medica 1980;61(11):844-57.

\section{Ceccato 1980 \{published data only\}}

Ceccato S, Cuginotta D, Carapezzi C, Ferretti G, Passeri M. Double-blind trial on the therapeutic effect of SAMe and ibuprofen [Studio clinico in doppio cieco sull'effetto terapeutico della SAMe e dell'Ibuprofen nella patologia degenerativa osteoarticolare.]. Giornale di Clinica Medica 1980;61(2):148-62.

Conis 2003 \{published data only\}

Conis E. Supplements. SAM-e may help mood, bone health. Los Angeles Times - Southern California Edition 2003; Vol. 27 October.

\section{Cucinotta 1980 \{published data only\}}

Cucinotta D, Mancini M, Ceccato S, Castino E, Cucinotta D, Mancini M, et al. Controlled clinical study of SAMe (Sadenosylmethionine) administered orally in degenerative osteoarticular pathology [Studio clinico controllato sull'attività della SAMe somministrata per via orale nella patologia degenerativa osteo-articolare ]. Giornale di Clinica Medica 1980;61(7):553-66.

\section{Fagan 2002 \{published data only\}}

Fagan EB, Latessa RA. S-adenosylmethionine (SAMe) is safe and effective for osteoarthritis. Journal of Family Practice 2002;51(8):667.

Pellegrini 1980 \{published data only\}

Pellegrini P, Pellegrini P. S-adenosylmethionine (SAMe) in osteoarthrosis; a double-blind crossover peroral study [La S-Adenosil-metionina (SAMe) nell'osteoartrosi studio in doppio cieco crossove per via orale.]. Giornale di Clinica Medica 1980;61(8):616-27.

\section{Polli 1975 \{published data only\}}

Polli E, Cortellaro M, Parrini L, Tessari L, Cherie Ligniere G, Polli E, et al. Pharmacological and clinical aspects of Sadenosylmethionine (SAMe) in primary degenerative arthropathy (osteoarthrosis) [Aspetti farmacologici e clinici della solfo-adenosil-metionina (SAMe) nella artropatia degenerativa primaria (osteoartrosi)]. Minerva Medica 1975;66:4443-59.

\section{Schardt 2003 \{published data only\}} Schardt D. SAM-e so-so. Nutrition Action Health Letter 2001;28:10-11.

\section{Schoenhals 2005 \{published data only\}}

Schoenhals K. Wellness. Supplements and functional food: SAMe I am: amino acid metabolite offers more than a mood boost. Better Nutrition 2005;67:47-8.

\section{Additional references}

\section{Altman 1996}

Altman R, Brandt K, Hochberg M, Moskowitz R, Bellamy N, Bloch DA, et al. Design and conduct of clinical trials in patients with osteoarthritis: recommendations from a task force of the Osteoarthritis Research Society. Results from a workshop. Osteoarthritis Cartilage 1996;4(4):217-43. 


\section{Bellamy 1995}

Bellamy N. Outcome measurement in osteoarthritis clinical trials. Journal of Rheumatology 1995;22(Suppl. 43):49-51.

\section{Capretto1985}

Capretto C, Cremona C, Canaparo L. A double-blind controlled study of S-adenosylmethionine (SAMe) v. ibuprofen in gonarthrosis, coxarthrosis and spondylarthrosis. Clinical Trials Journal 1985;22(1):15-24.

\section{Chinn 2000}

Chinn S. A simple method for converting an odds ratio to effect size for use in meta-analysis. Statistics in Medicine 2000;19(22):3127-31.

\section{Clegg 2006}

Clegg DO, Reda DJ, Harris CL, Klein MA, O'Dell JR, Hooper MM, et al. Glucosamine, chondroitin sulfate, and the two in combination for painful knee osteoarthritis. New England Journal of Medicine 2006;354(8):795-808.

\section{Cohen 1988}

Cohen J. Statistical power analysis for the behavioral sciences. 2nd Edition. Hillsdale, NJ: Lawrence Earlbaum Associates, 1988.

\section{DerSimonian 1986}

DerSimonian R, Laird N. Meta-analysis in clinical trials. Controlled Clinical Trials 1986;7(3):177-88.

\section{di Padova 1987}

di Padova C. S-adenosylmethionine in the treatment of osteoarthritis. Review of the clinical studies. American Journal of Medicine 1987;83(5A):60-5.

\section{Dickersin 1994}

Dickersin K, Scherer R, Lefebvre C. Identifying relevant studies for systematic reviews. BMJ 1994;309(6964):1286-91.

\section{Domljan 1989}

Domljan Z, Vrhovac B, Durrigl T, Pucar I, Domljan Z, Vrhovac B, et al. A double-blind trial of ademetionine vs naproxen in activated gonarthrosis. International Journal of Clinical Pharmacology, Therapy, \& Toxicology 1989;27(7):329-33.

\section{Egger 2001}

Egger M, Smith GD. Principles of and procedures for systematic reviews. In: Egger M, Smith GD, Altman DG editor(s). Systematic reviews in health care: meta-analysis in context. London: BMJ Books, 2001:23-42.

\section{Egger 2003}

Egger M, Juni P, Bartlett C, Holenstein F, Sterne J. How important are comprehensive literature searches and the assessment of trial quality in systematic reviews? Empirical study. Health technology assessment (Winchester, England) 2003;7(1):1-76.

\section{Fetrow 2001}

Fetrow CW, Avila JR. Efficacy of the dietary supplement S-adenosyl-L-methionine. Annals of Pharmacotherapy 2001;35(11):1414-25.

\section{Glorioso 1985}

Glorioso S, Todesco S, Mazzi A, Marcolongo R, Giordano M, Colombo B, et al. Double-blind multicentre study of the activity of S-adenosylmethionine in hip and knee osteoarthritis. International Journal of Clinical Pharmacology Research 1985;5(1):39-49.

\section{Guyatt 2008}

Guyatt GH, Oxman AD, Vist GE, Kunz R, Falck-Ytter Y, AlonsoCoello $P$, et al. GRADE: an emerging consensus on rating quality of evidence and strength of recommendations. BMJ 2008;336(7650):924-6.

\section{Hardy 2002}

Hardy M, Coulter I, Morton SC, Favreau J, Venuturupalli S, Chiappelli F, et al. S-Adenosyl-L-Methionine for treatment of depression, osteoarthritis, and liver disease. Evidence Report/Technology Assessment Number 64. (Prepared by Southern California Evidence-based Practice Center under Contract No. 290-97-0001). AHRQ Publication No. 02-E034 Rockville, MD: Agency for Healthcare Research and Quality. 2002, issue October:URL: http://www.ahrq.gov/clinic/tp/ sametp.htm\#Report (assessed 8 May 2008).

\section{Harmand 1987}

Harmand MF, Vilamitjana J, Maloche E, Duphil R, Ducassou D. Effects of S-adenosylmethionine on human articular chondrocyte differentiation. An in vitro study. American Journal of Medicine 1987;83(5A):48-54.

\section{Higgins 2003}

Higgins JP, Thompson SG, Deeks JJ, Altman DG. Measuring inconsistency in meta-analyses. BMJ 2003;327(7414):557-60.

\section{Higgins 2008}

Higgins JPT, Green S. Cochrane Handbook for Systematic Reviews of Interventions. Version 5.0.1 [updated September 2008]. The Cochrane Collaboration, 2008. Available from www.cochrane-handbook.org.

\section{Jüni 2001}

Jüni P, Altman DG, Egger M. Systematic reviews in health care: assessing the quality of controlled clinical trials. BMJ 2001;323(7303):42-6.

\section{Jüni 2006}

Jüni P, Reichenbach S, Dieppe P. Osteoarthritis: rational approach to treating the individual. Best Practice \& Research. Clinical Rheumatology 2006;20(4):721-40.

\section{Maccagno 1987}

Maccagno A, Di Giorgio EE, Caston OL, Sagasta CL, Maccagno A, Di Giorgio EE, et al. Double-blind controlled clinical trial of oral S-adenosylmethionine versus piroxicam in knee osteoarthritis. American Journal of Medicine 1987;83(5A):72-7.

\section{Marcolongo 1985}

Marcolongo R, Giordano N, Colombo B, et al. Double-blind multicenter study of the activity of S-adenosyl-methionine in hip and knee osteoarthritis. Current Therapeutic Research, Clinical and Experimental 1985;37(1):82-94. 


\section{Muller-Fassbender 1987}

Muller-Fassbender H, Muller-Fassbender H. Double-blind clinical trial of S-adenosylmethionine versus ibuprofen in the treatment of osteoarthritis. American Journal of Medicine $1987 ; 83(5 \mathrm{~A}): 81-3$.

\section{Najm 2004}

Najm WI, Reinsch S, Hoehler F, Tobis JS, Harvey PW, Najm Wadie I, et al. S-adenosyl methionine (SAMe) versus celecoxib for the treatment of osteoarthritis symptoms: a double-blind cross-over trial. BMC Musculoskeletal Disorders 2004;5:6.

\section{Nüesch 2009}

Nüesch E, Trelle S, Reichenbach S, Rutjes AW, Bürgi E, Scherer M, et al. The effects of the exclusion of patients from the analysis in randomised controlled trials: meta-epidemiological study. BMJ 2009;in press:-.

\section{Pham 2004}

Pham T, van der Heijde D, Altman RD, Anderson JJ, Bellamy N, Hochberg M, et al. OMERACT-OARSI initiative: Osteoarthritis Research Society International set of responder criteria for osteoarthritis clinical trials revisited. Osteoarthritis Cartilage 2004;12(5):389-99.

\section{Reichenbach 2007}

Reichenbach S, Sterchi R, Scherer M, Trelle S, Burgi E, Burgi U, et al. Meta-analysis: chondroitin for osteoarthritis of the knee or hip. Annals of Internal Medicine 2007;146(8):580-90.

\section{RevMan 2008 [Computer program]}

The Nordic Cochrane Centre. The Cochrane Collaboration. Review Manager (RevMan). Version 5.0. Copenhagen: The Nordic Cochrane Centre. The Cochrane Collaboration, 2008.

\section{Rucker 2008}

Rucker G, Schwarzer G, Carpenter JR, Schumacher M. Undue reliance on 12 in assessing heterogeneity may mislead. $B M C$ Medical Research Methodology 2008;8(1):79.

\section{Soeken 2002}

Soeken KL, Lee WL, Bausell RB, Agelli M, Berman BM. Safety and efficacy of S-adenosylmethionine (SAMe) for osteoarthritis. Journal of Family Practice 2002;51(5):425-30.

\section{Vetter 1987}

Vetter G, Vetter G. Double-blind comparative clinical trial with $\mathrm{S}$-adenosylmethionine and indomethacin in the treatment of osteoarthritis. American Journal of Medicine 1987;83(5A):78-80.

\section{Witte 2002}

Witte S, Lasek R, Victor N. Meta-analysis of the efficacy of adenosylmethionine and oxaceprol in the treatment of osteoarthritis [Wirksamkeit von Ademetionin und Oxaceprol fur die Behandlung von Arthrosen Eine Metaanalyse]. Orthopade 2002;31(11):1058-65.

\section{Wood 2008}

Wood L, Egger M, Gluud LL, Schulz KF, Juni P, Altman DG, et al. Empirical evidence of bias in treatment effect estimates in controlled trials with different interventions and outcomes: meta-epidemiological study. BMJ (Clinical Research Ed.) 2008;336(7644):601-5.

\section{CHARACTERISTICS OF STUDIES}

\section{Characteristics of included studies [ordered by study ID]}

Bradley 1994

Methods $\quad$ Randomised controlled trial

2-arm parallel group design

Trial duration: 4 weeks

Randomisation stratified according to centre

Multicentre trial with 2 centres

Power calculation: reported and protocol based for 3 pain scales

Funding by non-profit organisation: no information provided

Participants $\quad 48$ patients were randomised in study centre $A^{\star}, 33$ in study centre $B$

81 patients with osteoarthritis were reported at baseline

Affected joints: 81 knees

Number of females: 41 of $48(85 \%)$ in centre A, 7 of $33(21 \%)$ in centre B

Average age: 58 years in centre $A, 63$ years in centre $B$

Average disease duration: 10.9 years in centre $A, 12.4$ years in centre $B$

Radiographic severity of OA: (\% grade $2 / \%$ grade 3 ) in site A: $62.5 \% / 37.5 \%$ in SAMe, $54 \% / 46 \%$ in placebo. In site B: $59 \% / 41 \%$ in SAMe, $69 \% / 31 \%$ in placebo

Interventions

Experimental intervention: S-Adenosylmethionine, on 5 consecutive days intravenous $400 \mathrm{mg}$ once daily, then oral $200 \mathrm{mg} 3$ times daily

Control intervention: placebo, on 5 consecutive days intravenous once daily, then oral 3 times daily

Treatment duration: 4 weeks 
Bradley 1994 (Continued)

Analgesics other than study drugs allowed, intake assessed and found to be lower in SAMe group compared to placebo at site A, and higher in SAMe compared to placebo at site B.

\begin{tabular}{ll}
\hline Outcomes & $\begin{array}{l}\text { Extracted pain outcome: pain on walking after } 4 \text { weeks, described as "walking pain" } \\
\text { Extracted function outcome: walking disability after } 4 \text { weeks, described as "walking distance before } \\
\text { having to stop because of knee pain" } \\
\text { Primary outcome: > } 2 \text { reported; for HAQ pain, rest pain and walking pain }\end{array}$ \\
\hline Notes & $\begin{array}{l}\text { *In the original report the investigators presented results separately for site A and B, because the ran- } \\
\text { domisation, although concealed, resulted in marked baseline differences between patients at the } 2 \\
\text { sites with respect to demographic and disease related characteristics }\end{array}$ \\
\hline
\end{tabular}

\section{Risk of bias}

\begin{tabular}{|c|c|c|}
\hline Bias & Authors' judgement & Support for judgement \\
\hline $\begin{array}{l}\text { Adequate sequence gener- } \\
\text { ation? }\end{array}$ & Low risk & Use of random-number table \\
\hline Allocation concealment? & Low risk & Use of coded pharmacy \\
\hline Blinding of patients? & Low risk & $\begin{array}{l}\text { The trial was described as a double-blind study randomising patients to indis- } \\
\text { tinguishable interventions }\end{array}$ \\
\hline Blinding of physicians? & Unclear risk & No information provided \\
\hline $\begin{array}{l}\text { Blinding of outcome as- } \\
\text { sessors? }\end{array}$ & Unclear risk & No information provided \\
\hline $\begin{array}{l}\text { Interventions reported as } \\
\text { indistinguishable? }\end{array}$ & Low risk & $\begin{array}{l}\text { Quote: "Placebo Injectate and placebo tablets were employed that contained } \\
\text { the same stabilizers and inert ingredients as the active agent and were pack- } \\
\text { aged identically." }\end{array}$ \\
\hline $\begin{array}{l}\text { Double-dummy technique } \\
\text { used? }\end{array}$ & High risk & - \\
\hline $\begin{array}{l}\text { Intention-to-treat analysis } \\
\text { performed? } \\
\text { Pain }\end{array}$ & High risk & $\begin{array}{l}\text { Center A: no information provided. Center B: } 13 \text { out of } 17(76 \%) \text { in SAMe group, } \\
14 \text { out of } 16(87 \%) \text { in placebo group analysed. }\end{array}$ \\
\hline $\begin{array}{l}\text { Intention-to-treat analysis } \\
\text { performed? } \\
\text { Function }\end{array}$ & High risk & See above \\
\hline $\begin{array}{l}\text { Funding by commercial } \\
\text { organisation avoided? }\end{array}$ & High risk & Supported by a grant from Asta Medica \\
\hline
\end{tabular}

\section{Caruso 1987}

$\begin{array}{ll}\text { Methods } & \text { Randomised controlled trial } \\ \text { 3-arm parallel group design* } & \text { Trial duration: } 30 \text { days } \\ & \text { Randomisation stratified according to centre and type of joint } \\ \text { Multicentre trial with } 33 \text { centres } \\ \text { Power calculation: not reported }\end{array}$


Caruso 1987 (Continued)

Funding by non-profit organisation: no information provided

Experimental intervention: S-Adenosylmethionine, oral $200 \mathrm{mg} 6$ times daily
Control intervention: placebo, 6 times daily
Treatment duration: 4.2 weeks ( 30 days)
Analgesics other than study drugs not allowed

Outcomes Extracted pain outcome: global pain after 4 weeks, described as "diurnal pain"

Extracted function outcome: walking disability after 4 weeks, described as "degree of difficulty while walking on a plane"

No primary outcome reported

$\begin{array}{ll}\text { Notes } & \text { The trial arm with intervention naproxen was excluded from this review. Randomisation blocks num- } \\ \text { bered from } 19 \text { to } 24 \text { could only be used for enrolment of patients with spine and hand osteoarthritis. }\end{array}$

\section{Risk of bias}

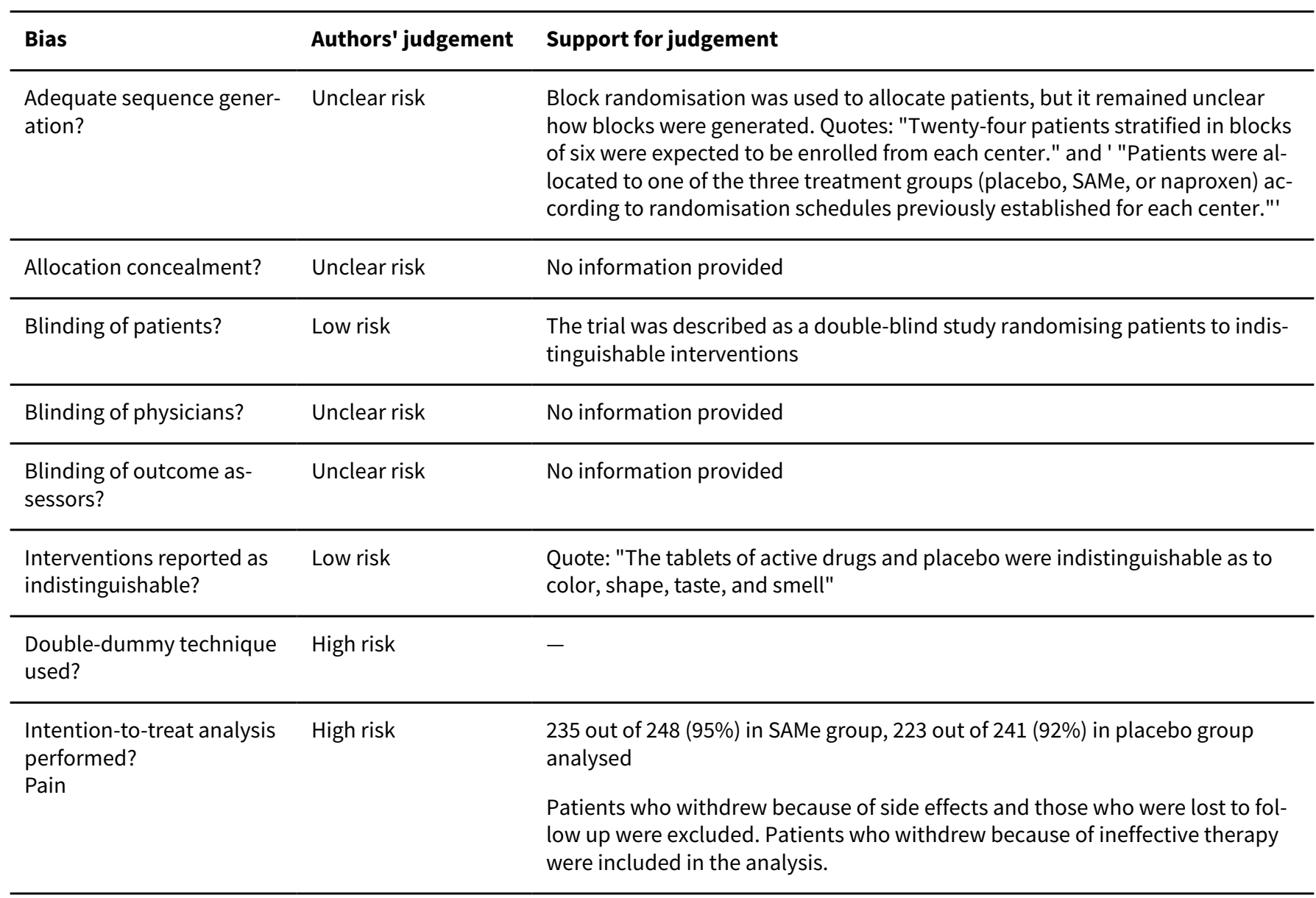


Caruso 1987 (Continued)

Intention-to-treat analysis High risk See above
performed?

Function

Funding by commercial High risk S-adenosylmethionine tablets were provided by BioResearch
organisation avoided?

König 1990

\begin{tabular}{ll}
\hline Methods & Randomised controlled trial \\
2-arm parallel group design & Trial duration: 12 weeks \\
Power calculation: not reported & Funding by non-profit organisation: no information provided
\end{tabular}

Participants 10 patients were randomised
10 patients with osteoarthritis were reported at baseline
Affected joints: 10 knees
Number of females: not reported
Average age: not reported, range 26 to 63 years
Average disease duration: not reported
Radiographic severity of OA: clinical evidence of osteoarthritis but without typical radiographic signs
(subchondral sclerosis, osteophytes, subchondral cysts)

Interventions

Experimental intervention: S-Adenosylmethionine (Gumbaral), $400 \mathrm{mg} 3$ times daily for 3 weeks, thereafter $400 \mathrm{mg}$ twice daily

Control intervention: placebo, 3 times daily for 3 weeks, thereafter twice daily

Treatment duration: 12 weeks

Unclear whether analgesics were allowed and the intake was assessed

\begin{tabular}{ll}
\hline Outcomes & $\begin{array}{l}\text { Reported pain outcome: pain on walking after } 12 \text { weeks, described as "walking without complaints" } \\
\text { Extracted function outcome: composite disability scores other than WOMAC after } 12 \text { weeks, described } \\
\text { as "7 items covering pain at night, morning stiffness, walking limitations, activity in daily life, local pain, } \\
\text { crepitation, flexion/extension" } \\
\text { No primary outcome reported }\end{array}$ \\
\hline Notes & $\begin{array}{l}\text { Not enough data provided for pain outcome to calculate standardised mean differences and the study } \\
\text { was therefore not included in the pain analyses. Contact with Dr Wacker was established, but he was } \\
\text { unable to provide additional data. Dr Wacker provided us the current e-mail address of Dr. König, but } \\
\text { latter did not reply to any of our e-mails. }\end{array}$
\end{tabular}

\section{Risk of bias}

\begin{tabular}{lll}
\hline Bias & Authors' judgement & Support for judgement \\
\hline $\begin{array}{l}\text { Adequate sequence gener- } \\
\text { ation? }\end{array}$ & Unclear risk & No information provided \\
\hline Allocation concealment? & Unclear risk & No information provided \\
\hline Blinding of patients? & Unclear risk & $\begin{array}{l}\text { Although the trial was described as double-blind, blinding of patients was not } \\
\text { specifically mentioned, nor were placebo tablets described as indistinguish- } \\
\text { able from active tablets }\end{array}$ \\
\hline Blinding of physicians? & Unclear risk & No information provided \\
\hline
\end{tabular}


König 1990 (Continued)

Blinding of outcome as- Unclear risk No information provided
sessors?

Interventions reported as High risk
indistinguishable?

\begin{tabular}{|c|c|c|}
\hline $\begin{array}{l}\text { Double-dummy technique } \\
\text { used? }\end{array}$ & High risk & - \\
\hline $\begin{array}{l}\text { Intention-to-treat analysis } \\
\text { performed? } \\
\text { Pain }\end{array}$ & High risk & 5 out of $6(83 \%)$ in SAMe group, 4 out of $4(100 \%)$ in placebo group analysed \\
\hline $\begin{array}{l}\text { Intention-to-treat analysis } \\
\text { performed? } \\
\text { Function }\end{array}$ & High risk & 5 out of $6(83 \%)$ in SAMe group, 4 out of $4(100 \%)$ in placebo group analysed \\
\hline $\begin{array}{l}\text { Funding by commercial } \\
\text { organisation avoided? }\end{array}$ & Unclear risk & No information provided \\
\hline
\end{tabular}

\section{Montrone 1985}

\begin{tabular}{ll}
\hline Methods & Quasi-randomised trial \\
2-arm parallel group design \\
Trial duration: 3 weeks \\
Power calculation: not reported \\
Funding by non-profit organisation: no information provided
\end{tabular}

Participants 76 patients were randomised
76 patients with osteoarthritis were reported at baseline
Affected joints: 51 knees and 25 hips
Number of females: not reported
Average age: not reported, range 40 to 75 years
Average disease duration: not reported, but more than 1 year
Radiographic severity of OA: functional classes II and IIl according to the classification of the American
Rheumatism Association (ARA)

Interventions Experimental intervention: S-Adenosylmethionine, $400 \mathrm{mg} 3$ times daily

Control intervention: placebo, 3 times daily

Treatment duration: 3 weeks

Unclear whether analgesics were allowed and the intake was assessed

\begin{tabular}{|c|c|}
\hline \multirow[t]{2}{*}{ Outcomes } & $\begin{array}{l}\text { Reported pain outcome: pain on activities other than walking after } 3 \text { weeks, described as "weight bear- } \\
\text { ing pain" } \\
\text { Reported function outcome: composite disability scores other than WOMAC after } 3 \text { weeks, described } \\
\text { as "pooled results from items: going upstairs and downstairs, standing up from chair, getting out of } \\
\text { bed" }\end{array}$ \\
\hline & No primary outcome reported \\
\hline Notes & $\begin{array}{l}\text { Not enough data provided for pain and function outcomes to calculate standardised mean differences } \\
\text { and the study was therefore not included in the main analyses. We were unable to retrieve contact de- } \\
\text { tails of the first, second and last author of the report. Sarzi-Puttini was contacted by e-mail, but he did } \\
\text { not reply. Further attempts by phone were unsuccessful. }\end{array}$ \\
\hline
\end{tabular}

\section{Risk of bias}

S-Adenosylmethionine for osteoarthritis of the knee or hip (Review) 
Montrone 1985 (Continued)

\begin{tabular}{|c|c|c|}
\hline Bias & Authors' judgement & Support for judgement \\
\hline $\begin{array}{l}\text { Adequate sequence gener- } \\
\text { ation? }\end{array}$ & Unclear risk & $\begin{array}{l}\text { This double blind trial was published in } 1985 \text { as a short letter to the editor of } \\
\text { Clinical Rheumatology. We assumed that treatment allocation was at random, } \\
\text { although the letter does not specifically mention the use of randomisation. }\end{array}$ \\
\hline Allocation concealment? & Unclear risk & See above \\
\hline Blinding of patients? & Low risk & $\begin{array}{l}\text { The trial was described as double-blind study randomising patients to indistin- } \\
\text { guishable interventions }\end{array}$ \\
\hline Blinding of physicians? & Low risk & $\begin{array}{l}\text { Physicians were blinded, as can be derived from the following quote "At the } \\
\text { end of the treatment in double-blind conditions, both the physician and pa- } \\
\text { tients expressed a judgment on the overall effectiveness of the therapy". }\end{array}$ \\
\hline
\end{tabular}

\begin{tabular}{ll}
\hline $\begin{array}{l}\text { Interventions reported as } \\
\text { indistinguishable? }\end{array}$ & Low risk \\
\end{tabular}

$\begin{aligned} & \text { Double-dummy technique } \\ & \text { used? }\end{aligned}$
$\begin{aligned} & \text { Intention-to-treat analysis } \\ & \text { performed? } \\ & \text { Pain }\end{aligned}$

Intention-to-treat analysis High risk 32 out of $39(82 \%)$ in SAMe group, 34 out of 37 (92\%) in placebo group analysed
performed?
Function

Funding by commercial Unclear risk $\quad$ No information provided
organisation avoided?

$\mathrm{HAQ}=$ health assessment questionnaire

$\mathrm{OA}=$ osteoarthritis

SAMe = S-Adenosylmethionine

Characteristics of excluded studies [ordered by study ID]

\begin{tabular}{ll}
\hline Study & Reason for exclusion \\
\hline Bottiglieri 2002 & No randomised controlled trial (review) \\
\hline Caroli 1980 & Only active control intervention (aspirin). Additional description: RCT \\
\hline Ceccato 1980 & Only active control intervention (ibuprofen). Additional description: RCT \\
\hline Conis 2003 & Not a randomised controlled trial (review) \\
\hline Cucinotta 1980 & Only active control intervention (ibuprofen). Additional description: RCT \\
\hline
\end{tabular}




\begin{tabular}{ll}
\hline Study & Reason for exclusion \\
\hline Fagan 2002 & No randomised controlled trial (review) \\
\hline Pellegrini 1980 & Only active control intervention (celecoxib). Additional description: RCT \\
\hline Polli 1975 & $\begin{array}{l}\text { Less than } 50 \% \text { of patients had osteoarthritis and it was unclear whether the study was a ran- } \\
\text { domised controlled trial }\end{array}$ \\
\hline Schardt 2003 & Not a randomised controlled trial (review) \\
\hline Schoenhals 2005 & Not a randomised controlled trial (review) \\
\hline
\end{tabular}

DATA AND ANALYSES

Comparison 1. S-Adenosylmethionine versus placebo

\begin{tabular}{|c|c|c|c|c|}
\hline Outcome or subgroup title & $\begin{array}{l}\text { No. of } \\
\text { studies }\end{array}$ & $\begin{array}{l}\text { No. of } \\
\text { partici- } \\
\text { pants }\end{array}$ & Statistical method & Effect size \\
\hline 1 Pain & 2 & 533 & $\begin{array}{l}\text { Std. Mean Difference (Random, 95\% } \\
\mathrm{Cl} \text { ) }\end{array}$ & $-0.17[-0.35,0.01]$ \\
\hline 2 Function & 3 & 542 & $\begin{array}{l}\text { Std. Mean Difference (Random, 95\% } \\
\mathrm{Cl} \text { ) }\end{array}$ & $0.02[-0.68,0.71]$ \\
\hline $\begin{array}{l}3 \text { Number of patients experiencing } \\
\text { any adverse event }\end{array}$ & 4 & 623 & Risk Ratio (IV, Random, 95\% Cl) & $1.27[0.94,1.71]$ \\
\hline $\begin{array}{l}4 \text { Number of patients who withdrew } \\
\text { because of adverse events }\end{array}$ & 4 & 656 & Risk Ratio (IV, Random, 95\% Cl) & $0.94[0.48,1.86]$ \\
\hline
\end{tabular}

Analysis 1.1. Comparison 1 S-Adenosylmethionine versus placebo, Outcome 1 Pain.

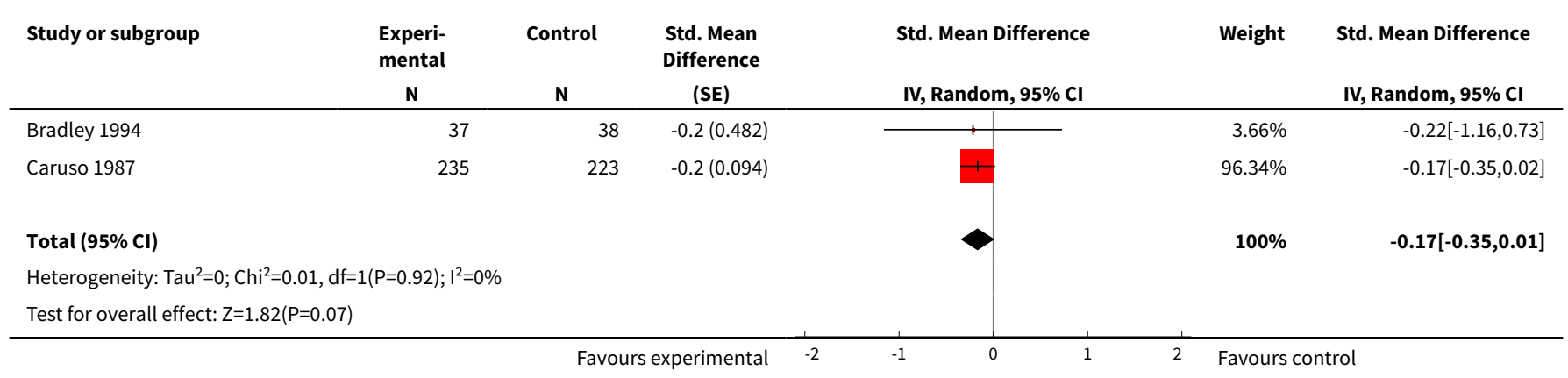


Analysis 1.2. Comparison $1 \mathrm{~S}$-Adenosylmethionine versus placebo, Outcome 2 Function.

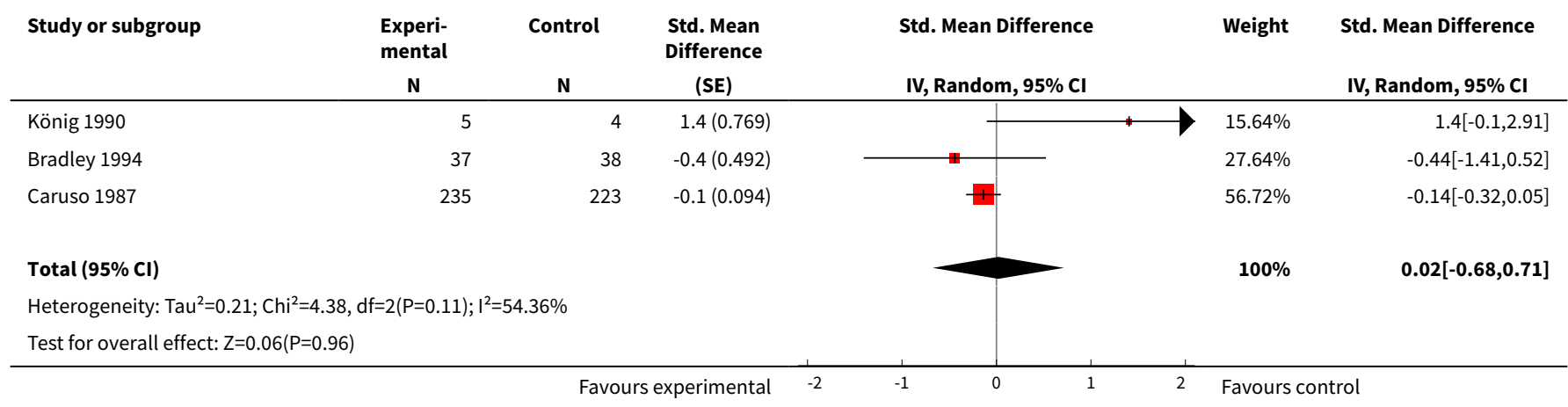

Analysis 1.3. Comparison $1 \mathrm{~S}$-Adenosylmethionine versus placebo, Outcome 3 Number of patients experiencing any adverse event.

\begin{tabular}{|c|c|c|c|c|c|}
\hline Study or subgroup & $\begin{array}{c}\text { Experimental } \\
n / N\end{array}$ & $\begin{array}{c}\text { Control } \\
n / N\end{array}$ & $\begin{array}{c}\text { Risk Ratio } \\
\text { IV, Random, 95\% CI }\end{array}$ & Weight & $\begin{array}{c}\text { Risk Ratio } \\
\text { IV, Random, 95\% CI }\end{array}$ \\
\hline König 1990 & $2 / 6$ & $0 / 4$ & & $1.12 \%$ & $3.57[0.21,59.39]$ \\
\hline Montrone 1985 & $3 / 39$ & $6 / 37$ & & $5.15 \%$ & $0.47[0.13,1.76]$ \\
\hline Bradley 1994 & $17 / 41$ & $11 / 40$ & $7=$ & $22.97 \%$ & $1.51[0.81,2.81]$ \\
\hline Caruso 1987 & $57 / 236$ & $42 / 220$ & & $70.76 \%$ & $1.27[0.89,1.8]$ \\
\hline \multicolumn{6}{|c|}{ Total events: 79 (Experimental), 59 (Control) } \\
\hline \multicolumn{6}{|c|}{ Heterogeneity: $\mathrm{Tau}^{2}=0 ; \mathrm{Chi}^{2}=2.98, \mathrm{df}=3(\mathrm{P}=0.39) ; \mathrm{I}^{2}=0 \%$} \\
\hline Test for overall effect & & & & & \\
\hline
\end{tabular}

Analysis 1.4. Comparison $1 \mathrm{~S}$-Adenosylmethionine versus placebo, Outcome 4 Number of patients who withdrew because of adverse events.

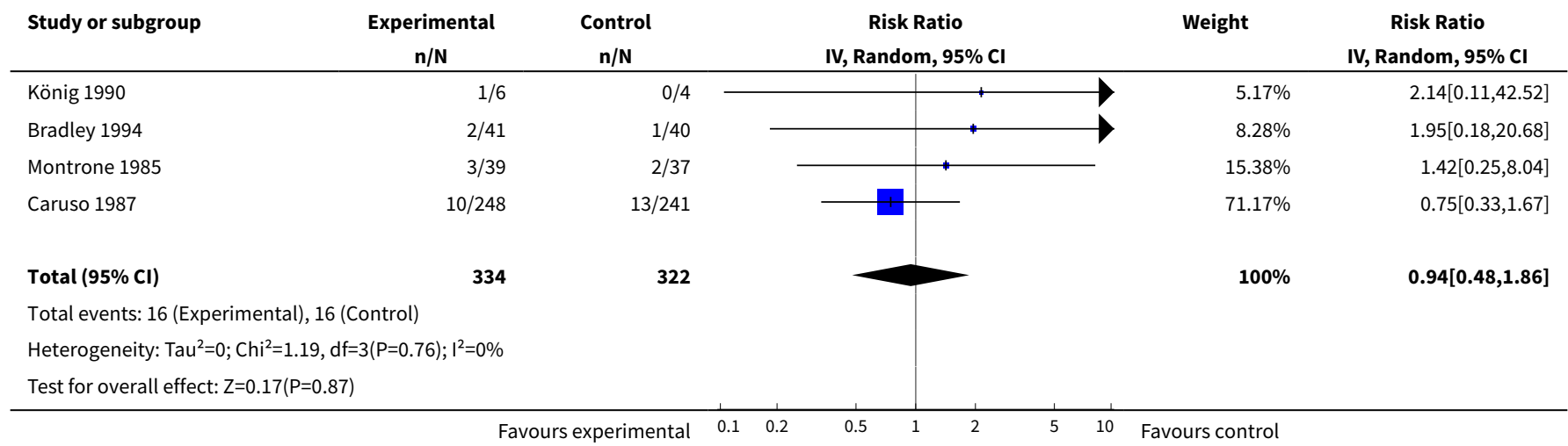




\section{A P P E N D C E S}

\section{Appendix 1. MEDLINE, EMBASE and CINAHL search strategy}

\begin{tabular}{|c|c|c|}
\hline OVID MEDLINE & OVID EMBASE & CINAHL through EBSCOhost \\
\hline Search terms for design & Search terms for design & Search terms for design \\
\hline 1. randomized controlled trial.pt. & 1. randomized controlled trial.sh. & 1. (MH "Clinical Trials+") \\
\hline 2. controlled clinical trial.pt. & 2. randomization.sh. & 2. (MH "Random Assignment") \\
\hline 3. randomized controlled trial.sh. & 3. double blind procedure.sh. & 3. (MH "Double-Blind Studies") or \\
\hline 4. random allocation.sh. & 4. single blind procedure.sh. & (MH "Single-Blind Studies") \\
\hline 5. double blind method.sh. & 5. exp clinical trials/ & 4. TX (clin\$ n25 trial\$) \\
\hline 6. single blind method.sh. & 6. (clin\$ adj25 trial\$).ti,ab. & 5. TX (sing $\$$ n25 blind\$) \\
\hline 7. clinical trial.pt. & 7. ((singl\$ or doubl\$ or trebl\$ or & 6. TX (sing\$ n25 mask\$) \\
\hline 8. exp clinical trial/ & tripl\$) adj25 & 7. TX (doubl\$ n25 blind\$) \\
\hline 9. (clin\$ adj25 trial\$).ti,ab. & (blind\$ or mask\$)).ti,ab. & 8. TX (doubl\$ n25 mask\$) \\
\hline 10. ((singl\$ or doubl\$ or trebl\$ or & 8. placebo.sh. & 9. TX (trebl\$ n25 blind\$) \\
\hline tripl\$) adj25 (blind\$ or & 9. placebo\$.ti,ab. & 10. TX (trebl\$ n25 mask\$) \\
\hline mask\$)).ti,ab. & 10. random\$.ti,ab. & 11. TX (tripl\$ n25 blind\$) \\
\hline 11. placebos.sh. & 11. methodology.sh. & 12. TX (tripl\$ n25 mask\$) \\
\hline 12. placebo\$.ti,ab. & 12. comparative study.sh. & 13. (MH "Placebos") \\
\hline 13. random\$.ti,ab. & 13. exp evaluation studies/ & 14. TX placebo\$ \\
\hline 14. research design.sh. & 14. follow up.sh. & 15. TX random\$ \\
\hline 15. comparative study.sh. & 15. prospective study.sh. & 16. (MH "Study Design+") \\
\hline 16. exp evaluation studies/ & 16. (control\$ or prospectiv\$ or & 17. (MH "Comparative Studies") \\
\hline 17. follow up studies.sh. & volunteer\$).ti,ab. & 18. (MH "Evaluation Research") \\
\hline 18. prospective studies.sh. & & 19. (MH "Prospective Studies+") \\
\hline \multirow[t]{2}{*}{$\begin{array}{l}\text { 19. (control\$ or prospectiv\$ or } \\
\text { volunteer\$).ti,ab. }\end{array}$} & & $\begin{array}{l}\text { 20. TX (control\$ or prospectiv\$ or } \\
\text { volunteer\$) }\end{array}$ \\
\hline & & 21. $\mathrm{S} 1$ or $\mathrm{S} 2$ or $(\ldots \ldots .$.$) or \mathrm{S} 20$ \\
\hline
\end{tabular}

\section{Search terms for Osteoarthritis}

20. exp osteoarthritis/

21. osteoarthriti\$.ti,ab,sh.

22. osteoarthro\$.ti,ab,sh.

23. gonarthriti\$.ti,ab,sh.

24. gonarthro\$.ti,ab,sh.

25. coxarthriti\$.ti,ab,sh.

26. coxarthro\$.ti,ab,sh.

27. arthros\$.ti,ab.

28. arthrot\$.ti,ab.

29. ((knee\$ or hip\$ or joint\$) adj3 (pain\$

or

ach\$ or discomfort\$)).ti,ab.

30. ((knee\$ or hip\$ or joint\$) adj3 stiff

\$).ti,ab.
Search terms for Osteoarthritis

17. exp osteoarthritis/

18. osteoarthriti\$.ti,ab,sh.

19. osteoarthro\$.ti,ab,sh.

20. gonarthriti\$.ti,ab,sh.

21. gonarthro\$.ti,ab,sh.

22. coxarthriti\$.ti,ab,sh.

23. coxarthro\$.ti,ab,sh.

24. arthros $\$$.ti, ab.

25. arthrot $\$$.ti,ab.

26. ((knee\$ or hip\$ or joint\$) adj3

(pain\$ or ach\$ or

discomfort\$)).ti,ab.

27. ((knee\$ or hip\$ or joint\$) adj3 stiff\$).ti,ab.
Search terms for Osteoarthritis

22. osteoarthriti\$

23. (MH "Osteoarthritis")

24. TX osteoarthro\$

25. TX gonarthriti\$

26. TX gonarthro\$

27. TX coxarthriti

28. TX coxarthro\$

29. TX arthros\$

30. TX arthrot\$

31. TX knee\$ $n 3$ pain\$

32. $T X$ hip $\$ n 3$ pain $\$$

33. TX joint $\$ n 3$ pain $\$$

34. TX knee $\$ 3$ ach\$

35. TX hip $\$ \mathrm{n} 3$ ach\$

36. $T X$ joint $\$ n 3$ ach\$

37. TX knee\$ n3 discomfort\$

38. TX hip $\$ \mathrm{n} 3$ discomfort\$

39. $T X$ joint $\$ n 3$ discomfort $\$$

40. TX knee\$ n3 stiff\$

41. TX hip $\$ \mathrm{n} 3$ stiff\$

42. $T X$ joint $\$ 3$ stiff\$

43. $\mathrm{S} 22$ or $\mathrm{S} 23$ or $\mathrm{S} 24 \ldots$... or $\mathrm{S} 42$
Search terms for S-Adenosylmethionine

31. exp S-Adenosylmethionine/
Search terms for S-Adenosylmethionine

28. exp S-Adenosylmethionine/
Search terms for S-Adenosylmethionine

44. (MH "S-Adenosylmethionine") 
(Continued)

32. Sadenosylmethionine.tw.

33. S-adenosylmethionine.tw.

34. Adenosyl-l-met*ionine.tw.

35. ademet*ionin ${ }^{\star}$.tw.

36. methionine.tw

37. metionine.tw

38. heptral.tw.

39. Adomet.tw.

40. Gumbaral.tw.

41. SAM-e.tw.

42. Transmetil.tw.

43. SD4.tw.

44. Samyr.tw.
29. Sadenosylmethionine.tw.

30. S-adenosylmethionine.tw.

31. Adenosyl-l-met*ionine.tw.

32. ademet*ionin*.tw.

33. methionine.tw

34. metionine.tw

35. ademetionin*.tw.

36. heptral.tw.

37. Adomet.tw.

38. Gumbaral.tw.

39. SAM-e.tw.

40. Transmetil.tw.

41. SD4.tw.

42. Samyr.tw.
45. TX Sadenosylmethionine

46. TX S-adenosylmethionine

47. TX Adenosyl-l-met*ionine

48. TX ademet*ionin*

49. TX methionine

50. TX metionine

51. TX heptral

52. TX Adomet

53. TX Gumbaral

54. TX SAM-e

55. TX Transmetil

56. TX SD4

57. TX Samyr

58. S44 or S45 or .... S57

\section{Combining terms}

Combining terms

42. or/1-16

43. or $/ 17-27$

44. or/28-41

45. and $/ 42-44$

46. animal/

47. animal/ and human/

48.46 not 47

49. 45 not 48
Combining terms

S21 and S43 and S59

\section{Appendix 2. CENTRAL search strategy}

\section{CENTRAL}

\section{Search terms for Osteoarthritis}

\#1. (osteoarthritis* OR osteoarthro* OR gonarthriti ${ }^{\star}$ OR gonarthro*

OR coxarthriti* OR coxarthro* OR arthros* OR arthrot* OR

((knee* OR hip* OR joint $\left.{ }^{\star}\right)$ near/3 (pain* OR ach* OR discomfort $\left.\left.{ }^{\star}\right)\right)$

OR ((knee* OR hip* OR joint $\left.{ }^{\star}\right)$ near/3 stiff $)$ ) in Clinical Trials

\#2. MeSH descriptor Osteoarthritis explode all trees

\section{Search terms for S-Adenosylmethionine}

\#3. MeSH descriptor S-Adenosylmethionine explode all trees

\#4. Sadenosylmethionine in Clinical Trials

\#5. S-adenosylmethionine in Clinical Trials

\#6. Adenosyl-I-met*ionine in Clinical Trials

\#7. ademet*ionin ${ }^{*}$ in Clinical Trials

\#8. methionine.tw in Clinical Trials

\#9. metionine.tw in Clinical Trials

\#10. heptral in Clinical Trials

$\# 11$. Adomet in Clinical Trials

\#12. Gumbaral in Clinical Trials

\#13. SAM-e in Clinical Trials

$\# 14$. Transmetil in Clinical Trials

\#15. SD4 in Clinical Trials

\#16. Samyr in Clinical Trials

\section{Combining terms}

\#17. (\#3 OR \#4 OR \#5 OR \#6 OR \#7 OR \#8 OR \#9 OR \#10 OR

S-Adenosylmethionine for osteoarthritis of the knee or hip (Review) 


\section{WHAT'S NEW}

\begin{tabular}{lll}
\hline Date & Event & Description \\
\hline 1 May 2008 & Amended & CMSG ID C178-R \\
\hline
\end{tabular}

\section{CONTRIBUTIONS OF AUTHORS}

Study conception: Rutjes, Jüni

Protocol development: Rutjes, Nüesch, Reichenbach, Jüni

Acquisition of data: Rutjes, Nüesch, Reichenbach

Analysis and interpretation of data: Rutjes, Nüesch, Reichenbach, Jüni

Drafting of the manuscript: Rutjes, Jüni

Critical revision of the manuscript for important intellectual content: Rutjes, Nüesch, Reichenbach, Jüni

Statistical analysis: Nüesch, Rutjes, Jüni

Obtained funding: Reichenbach, Jüni

\section{DECLARATIONSOF INTEREST}

None.

\section{SOURCES OF SUPPORT}

\section{Internal sources}

- Institute of Social and Preventive Medicine, University of Bern, Switzerland.

Intramural grants

\section{External sources}

- Swiss National Science Foundation, Switzerland.

National Research Program 53 on musculoskeletal health (grant numbers 4053-40-104762/3 and 3200-066378)

\section{DIFFERENCES BETWEEN PROTOCOLANDREVIEW}

Before embarking on this review, we generated a standard protocol for this, and all other Cochrane Reviews performed by our group. The protocol was approved by the Editorial Board of the Cochrane Musculoskeletal Review Group (CMSG). Due to the low number of trials included, we had to deviate from the original protocol in some aspects. We could not explore the association between trial size and treatment effects with funnel plots and could not perform stratified analyses, which were planned to evaluate if treatment effects on pain and function were affected by type of control (placebo or sham intervention versus no intervention), concealment of allocation (adequate versus inadequate or unclear), blinding of patients (adequate versus inadequate or unclear), analysis in accordance with the intention-totreat principle (yes versus no or unclear), trial size, funding, and differences in the use of co-interventions in the trial groups. In addition, we anticipated including dosage of intervention as continuous variables at trial level. Finally, visual inspection revealed a potential outlier in the heterogeneous meta-analysis of function and we performed a sensitivity analysis excluding this outlier as required by one of the peer reviewers. 


\section{N D EX TERMS}

\section{Medical Subject Headings (MeSH)}

Arthralgia [ ${ }^{\star}$ drug therapy]; Osteoarthritis, Hip [ ${ }^{*}$ drug therapy]; Osteoarthritis, Knee [ ${ }^{*}$ drug therapy]; Randomized Controlled Trials as Topic; S-Adenosylmethionine [adverse effects] [ ${ }^{\star}$ therapeutic use]

\section{MeSH check words}

Humans 